\title{
Los pobres como lugar teológico
}

\author{
JOSE IGNACIO GONZALEZ FAUS \\ Sent Cugat del Vallés (Barcelona).
}

\section{Introduccion}

Hablar de "lugares teolbgícos" comporta un peligro confirmado por la experiencia. Durante mucho tiempo, el concebir a la Escritura y a la tradición como lugares teológicos pudo equivaler a mitificarlas, a abstraerlas de la historia humana, a leerlas como palabras mecánicas de oráculo, a substraerlas a todo análisis racional o científico que encuentra en ellas las mismas leyes de creación de toda palabra humana en la historia. De modo que la Biblia sólo podia ser llamada "palabra de Dios" al precio de negar en la práctica su dimensión de palabra humana; y la tradición sólo podía estar "asistida por el Espíritu Santo" a costa de no ser obra del espiritu humano. No debió ser así, pero de hecho lo fue. Y no es preciso evocar, porque son conocidas, las resistencias ante cualquier aplicación a los "lugares teológicos" de los métodos epistemológicos humanos, tanto de orden histórico cientifico, como de carácter hermenéutico.' Tampoco queremos decir que tales resistencias no tengan argumentos válidos en sí mismos y de los que echar mano: ; claro que hay un uso de la ciencia que convierte a la palabra de Dios en objeto y al exegeta en juez en lugar de creyente! Pero, por cierto que sea ese riesgo, no es legítimo querer escapar de él refugiándose en una idolatria o sacralización de-las mediaciones.

¿Por qué negar que todo este peligro puede volver a repetirse si hablamos de los pobres como "lugar teológico"? De hecho, casi todas las acusaciones modernas contra la teologia de la liberación han esgrimido este mismo argumento: arguyen que se milifica al pobre, que se evacúa la pecaminosidad o al menos la ambigüedad del pobre, que se absolutiza al pobre optando por él de manera excluyente... Cuando hace pocos años, en su Teología negra, un hombre del vigor teológico de James Cone, habló expresamente de la negritud como lugar teológico, sería dificil negar que anduvo rozando este mismo escollo. ${ }^{2}$ Y esta mitificación del oprimido se dio igualmente cuando, en un con- 
texto anticonfesional, K. Marx habló del proletariado no como “lugar teológico," pero si como lugar epistemológico, transformador y revolucionario. Porque, en el fondo, ambos modos de hablar vienen a decir lo mismo: el uno en registro creyente y el otro en un registro sediente ateo. La concepcion marxiana del proletariado como "universal negativo," - por estar privado no de tal o cual aspecto de lo humano, sino de la totalidad de lo humano- llevaba incluida, para el joven Marx, la promesa de que al "ponerlo del revés" se realizaría la universalidad positiva: el proletariado era por eso aquella clase que, al liberarse a sí misma, liberaba aulomáticamente todo lo demás y a todos los demás. ${ }^{3}$ La acuñación teológica de este modo de ver las cosas es innegable. $Y$ las teologias, cuando se proclaman ateas, son todavia más peligrosas que cuando son creyentes; pues en el primer caso son inconscientes del vértigo que produce su pretendida elevación teológica, mientras que en el segundo caso eslán obligadas a esa sujección del discurso teológico al Dios del que dicen hablar, pero al que reconocen no poder expresar; y, con ello, proclaman la intrínseca relalivización de sí mismas en el momento misino en que se llaman teologías. ${ }^{4}$ Volviendo al Marx joven, de lo que no se dio cuenta el autor de $L a$ cuestion judia es de que ese "universal negativo," al ponerlo del revés, dejaba necesariamente de ser universal. No hay positividad universal en este mundo. Y para un ateo todavía menos, por definición. Las consecuencias prácticas de este pequeño olvido ya son suficientemente conocidas, como para que aquí nos entretengamos con ellas.

Pero si que es preciso notar esto otro: quienes, con razón reaccionan hoy contra esa mitificación del pobre y, como conclusión, pasan de ahí a negarle su carácter de "lugar teológico," cometen exactamente el mismo pecado que todos aquellos cientistas o racionalistas "ilustrados" que, al descubrir el elemento "humano" de Escritura y tradición, acabaron por negarles todo su carácter de "palabra de Dios" y su diferencia constitutiva respecto a otros frutos del espíritu humano. Esto es lo que hoy hacen muchos con los pobres, unas veces por afán ortodoxo y otras por afán ilustrado, pero en cualquier caso, eliminando con ello la revelación de Dios, y convirtiéndose de obedientes en jueces. Con el riesgo claro de acabar convirtiéndose inconsciente e involuntariamente a sí mismos en lugar tcológico...

Y sin embargo, para la fe cristiana es tan fundamental el que los pobres son un "lugar teológico" como el que la Biblia pueda ser llamada "palabra de Dios". Por eso se hace imprescindible el esfuerzo por recuperar ese carácter teológico, tratando de mostrar en qué consiste.

Nuestra exposición tendrá tres partes muy diversas y complementarias. Una de corte más bien negativo: los pobres son lugar teológico porque llevan a cabo la desirucción de muchos falsos "lugares teológicos" que son inconscientes y en los que el hombre se enreda y su razón peca. Dicho de manera más sencilla: habremos de hablar del pobre como destruccion de nuestros "mecanismos de defensa ante Dios," como destrucción por ello de nuestras falsificaciones idolátricas. Daremos a esta primera parte un carácter más bíblico, y trataremos de mostrar cómo, para el evangelio de Juan, el falso lugar teológico en que están situados "los judios" (como llama el cuarto evangelio a los in- 
terloculores de Jesús), y que es su carácter de beneficiados del poder romano, es el que les impide reconocer a Dins, ya sea en el paralitico que camina, o en el pueblo que se alimenta, o en el ciego que recobra la luz, o hasta en el muerto que vuelve a la vida. Esta parte será sólo un apunte breve. Luego, en una segunda parte de corte unás positivo, y más materialmente centrada en el terna de los pobres, buscaremos los aspectos que pueden permitirnos hablar del pobre como lugar teológico. Hablaremos entonces del pobre como theologia crucis (1); del pobre como revelador del Gran Pobre que es el Amor (2); y del pobre como revelación de la gloria de Dios; gloria Dei rivens pauper (3). El hilo de la exposición nos obligará a enfrentarnos, en una tercera parte, con las relaciones entre opción por el pobre y justificación por la fe. Y de toda esta exposición se seguirán algunas consecuencias importantes y serias para la fe cristiana en la cultura moderna.

\section{El pobre como juicio contra los piadosos}

Comencemos pues mostrando que la opción por el pobre forma parte de ese "obrar la verdad" o de ese "amor a la luz" que no son sólo consecuencias de la fe en Jesús sino que, para San Juan, son también factores decisivos en la aceplación de Jesús.

Supongo que, para hacer más entrable a Juan en este contexto, tendría que haber dicho más bien: la opción por el hombre, o la opción por la noopresión del hombre sobre el hombre, o la opción por los hermanos... o un lenguaje de este tipo que nos acercaria mucho más a la frase clásica del mundo joánico: "quien no ama $a$ su hermano al que ha visto, no puede amar a Dios a quien no ha visto" ( $\mathrm{I} \mathrm{Jn.} \mathrm{4,20).}$

Si yo he puesto "los pobres" y no el hombre o el hermano es porque creo que, desde el momento en que aparecen en la historia los pobres, y en los niveles actuales (sólo de muertos de hambre: 1 ó 2 por segundo...), entonces la opción por el hombre y por el hermano se vuelve necesariamente parcializada y debe dirigirse preferentemente a los pobres. Se trata, pues de aplicar a la frase cilada de I Jn. 4,20 este otro principio que no solamente parece de humanidad elemental, sino que proviene también de aquella práctica de Jesús que buscaba reintegrar a las ovejas perdidas. Mi hermano no es aquél que yo me busco o que lleva mi sangre, sino el que necesita de mi [raternidad: así podriamos formularlo paralraseando la parábola del buell samaritano. De acuerdo con esto, amar al pobre no es una cosa ni distinta, ni sobreañadida al amor al hermano de que habla Juan: en el mundo de hoy, es simplemente el criterio verificador del amor al hombre y al hermano. Es el que dice que todo amor-al-hombre que prescinde de "éstos" es en realidad una de estas dos cosas: o amor a si mismo o amor, no al hombre real (el que "se ve"), sino a un hombre ideal (al que "no se ve" como tampoco se ve a Dios). Y por tanto, en cualquiera de los dos casos, no cumple con la condición citada de la I Jn. 4,20 sobre el amor al hermano a quien se ve. 


\section{Elementos característicos del cuarto evangelio}

Hecha esta aclaración debemos comenzar asentando un rasgo de la teología joánica, que la distingue de los sinópticos, y que (para algunos) la hace poco interesante hoy. Podriamos formularlo asi: Juan no habla del reino, sino de la fe en Jesús. Esto creo que está claro. El esquema teológico sinóptico, con todas sus variantes ulteriores, nosotros lo miramos más o menos asi: Jesús anunció el reino, vinculó a Dios con él, y - a pesar de su muerte- tras su resurrección ese reino irrumpió de algún modo, y vive para nosotros que "hemos sido trasladados a él" (cf. Col. 1,13). A este esquema no solamente le damos relieve teológico, sino una cierta historicidad básica: estos son para nosotros "los hechos cristianos."

Juan no parece moverse por ahi: lo que viene para él, tras la muerte y resurrección de Jesús no es el reino anunciado, sino la fe en Jesús. La frase de Jn 18,36: "mi reino no es de este mundo" es casi la única vez en que sale la Basileia en Juan y por su misma naturaleza parece contrastar radicalmente con la otra frase que inaugura el evangelio de Marcos $(1,15)$ : "convertios porque llega el reino."

Y por eso, mientras para los sinópticos el demonio está vencido en los milagros de Jesús que serian como las trompetas que anuncian el reino (recordar Mi. 12,28: "si yo lanzo los demonios... es que llega a vosolros el reino de Dios"), en cambio para el mundo joánico, el demonio no está vencido en esas realizaciones de reino, pues ésılas han sido de algún modo derroladas en la muerte de Jesús; sino que "ésta es la victoria que vence al mundo: nuestra fe" $(1 \mathrm{Jn} .5,4)$. Y porque el demonio no está históricamente vencido, sospecho yo que es por lo que Juan no cuenta curaciones de endemoniados: el demonio ha pasado a ser lo mismo que "el mundo" y el único verdadero exorcismo es la persona de Jesús y la fe en él.

Por esta razón, los milagros no son para Juan fuerzas o ecos del reino que viene y que brotan de la fe-en-el-reino, (como lo son en Marcos), sino que son signos de que la causa de Jesús queda victoriosa a pesar de su derrota, es decir, a pesar de la crucifixión de Jesús. Y como signos, pueden llevar a la fe; "se escribieron éstos (milagros) para que crean que Jesús es el Hijo de Dios, y creyendo tengan vida" (Jn. 20,31); la vida es la primera característica del Reino, puesto que la muerte es el dominio de Satán.

Y subrayo lo de "pueden" porque, en mi modesta opinión, para Juan tampoco llevan demasiado. Precisamente porque el reino no es de este mundo, para verlo hay que "renacer de nuevo" (Jn. 3,3). Y por eso para que los milagros lleven a la fe, hay que pasar - según Juan- por esa derrota de la muerte (que, aunque Juan la describa como casi milagrosa e indolora, es en si misma el supremo antimilagro). Los signos sólo llevan a la fe a los que aceptan esa inversion valoral de que algo tan derrotante como la muerte, es victoria: no llevarán a la fe (ni siquiera para Juan) a los que no pasan por la pasión, pues a éstos les llevan más bien a una de estas dos posturas increyentes: a la manipulación del signo para comer ellos $(\mathrm{Jn}, 6,26)$ o al abuso del signo para creer viendo 
(Jn. 4,48 y 20,29$)$ y al endurecimiento de los que se cierran a toda consideración y a todo diálogo, porque entrevén que podrian venir los romanos y acabar con la situación de que ellos son beneficiarios ( $\mathrm{J} n$. 1,48-50), o se asustan cuando ven que un ignorante puede venir a darles lecciones sobre Dios $(\mathrm{Jn} .9,34)$.

Huelga decir que, vista desde nuestro occidente, la primera puede ser la postura de la izquierda que no esıá en el poder, y la otra, la posiura de aquellos que están en el poder. Y de este núcleo leológico, creo yo que se siguen dos consecuencias que ya no sé si las dice Juan, pero que a fectan a nuestro tema. Voy a exponerlas en los dos apartados siguientes.

\section{A la fe no se llega sin obra}

Por supuesto la formulación es provocativa, por el afán de usar las palabras fe y obras, que tienen otro contexto tan paulino y tan distinto que parece ser su única casa posible. Pero lo que quiero decir es sólo esto: si los "signos" de Jesús sólo llevan a la le a quienes pasan por esa derrota de su pasión, hemos de decir que para Juan hay algo que es, en algún sentido, previo a la le explicita, a saber; ese "volver a nacer" $(\mathrm{Jn}, 3,3)$ que se da en el paso por la pasión. Algo que es previo a la fe como conocimiento de la verdad; y este algo es el "practicar la verdad" (Jn. 3,21):

La fe es denominada en este evangelio "conocimiento de la verdad" $(8,32)$, pero, como se puede mostrar fácilmente, esta denominación es más restringida que la de "obrar la verdad" $y$, en el fondo, conocer la verdad es un momento de obrar la verdad un momento de venir a la luz.'

¿Qué será entonces ese "practicar la verdad" que es previo o más amplio que el "conocer la verdad" y que, al poseer la verdadera calidad de la fe, es el que decide sobre la fe expresa?

Yo diría, (quizás ya no lo dice Juan, pero me parece que se deduce de él) que el que practica la verdad es el que, cuando la luz viene al mundo $(\mathrm{Jn} .3,19)$, "va él a la luz" $(3,21)$. Y va a la luz con sus obras $(3,21)$, es decir, porque sus obras son un "ir a la luz." Obrar la verdad equivale a la expresión de Gustavo Gutiérrez: "practicar a Dios", —que parece molestar a alguno de sus criticos- pero entendiendo que "practicar a Dios" no es practicar el éxito, sino practicar el fracaso, en el sentido siguiente: es practicar la causa de Dios (el reino) que lleva a quien la practica a ese fracaso al que llevó a Jesús. Por tanto, no cualquier fracaso es obrar a Dios, sino soblo el que surge como rechazo por los hombres del Dios de vida-para-todos. Y por eso, para Juan, el dilema del hombre parece ser éste, o cree (lo cual indica que ha ido a la luz), o queda ya juzgado al no creer, pues eso indica que no ha ido a la luz porque "amaba más las tinieblas ya que sus obras eran malas' ' $(3,20)$.

Quedaría por saber si -y cómo- ese concepto de las obras malas se contrapone en Juan al de las obras de Jesús, expresión super repetida y que viene a sustituir a la del reino en los sinópticos. Pues lo de las obras de los judios aparece en varios otros momentos: por ejemplo 8,41, aunque profesen tener la fe de Abraham, en realidad son del diablo, pues hacen las obras de és- 
te. Tendriamos entonces que, cuando el hombre no hace las obras de Jesús (del reino), no va a la luz y por eso no tendrá la luz y no creerá. Lo cual se parece bastante a la tesis de Marcos de que a Jesús sólo se le conoce siguiéndolo, aunque esté dicho de forma mucho más evolucionada, como suele pasarle a Juan respecto de Marcos.

Volviendo a nuestra reflexión, hay que añadir que esa consecuencia a que llega Juan (o se cree, o se está ya juzgado), nos parece a nosotros sectaria y choca con nuestra mentalidad de respeto a la increencia. Por eso es preciso explicar que la tesis de Juan no vale sin más para la increencia actual, la cual tiene otras mil causas culturales, desde la ingnorancia de la predicación hasta el hecho de que la presencia de la Iglesia pecadora no tiene la misma transparencia que la presencia de Jesús. Y por tanto, la concepción de Juan no vale para el diálogo moderno fe-cultura o, al menos, no vale total y exclusivamen$t e$; si bien en algún nivel del hombre y del mundo moderno también será desenmascarable algún "amor a las tinieblas," aunque esté mezclado con otros factores. La tesis de Juan vale en el contexto de la discusión de Jesús "con los de dentro," o con "los judíos," en el léxico del cuarto evangelio. Y por lo tanto, para nosotros podria tener más aplicación en el seno del mundo cristiano. $\mathbf{Y}$ entonces viene una de las preguntas que preocupan a este escrito: si la práctica social de occidente, es una práctica de tinieblas (por ejemplo en cuanto es "productora de ricos cada vez más ricos a costa de pobres cada vez más pobres," como dijeron Juan Pablo II y Puebla), entonces la descristianización de occidente ihay que atribuirla a algún agente secreto "exterior" a la Iglesia -moscovita o masónica- o más bien es simplemente el juicio de Dios sobre este occidente, juicio inmanente al occidente mismo?

\section{La falta de fe, como juicio}

Precisamente por eso, hay que decir también que, para Juan, tras la muerte de Jesús lo que viene no es ciertamente el reino, pero tampoco es solo la fe. Esto sonaría a cierta consolación arbitraria o voluntarista. Pero con la muerteresurrección de Jesús ha llegado además un juicio de condena sobre este mundo que ha rechazado al reino porque amaba más las tinieblas; y amaba más las tinieblas porque sus obras eran malas. El hecho de que el mundo haya matado a Jesús es la prueba decisiva de la maldad de sus obras; pues solo quien obraba mal podía matar a Jesús. La condena de Jesús no es una maldad puntual, nueva, e independiente del resto de la vida de quienes lo matan, como si sólo ahi (en el matar o no matar a Jesús) se jugase el hombre el ser bueno o malo. La condena de Jesús es revelación de la vida anterior (del pecado del mundo). Y subrayo esto porque me temo que los cristianos tendemos a entenderlo de la otra manera y, como históricamente no hemos matado'a Jesús, convertimos lo que es un evangelio "contra nosotros," en un evangelio contra los demás y a favor de nosotros mismos.

De hecho, parece que todos los comentaristas están bastante de acuerdo en que el cuarto evangelio tiene este carácter de juicio, y un juicio donde, en realidad, nadie condena desde fuera, o como enemigo exterior, sino que son los 
acusados los que se condenan a si mismos. Ahora bien, nadie se condena a si mismo explicitamente; pues entonces esa condena sería ya arrepentimiento. La única manera de que alguien se condene a si mismo es que, sin quizás darse cuenta él, vaya quedando desenmascarado. Se puede decir entonces que el cuarto evangelio es como un proceso de desenmascaramiento, recordar que Satán es mentiroso y padre de la mentira $(\mathrm{Jn} .3,44)$ y que antes hemos establecido una cierta identificación entre Satán y "el mundo este."

Esle proceso de desenmascaramiento lienc al menos dos momentos bien sonados: el de 11,47-50 (es mejor cue muera un hombre a que vengan los romanos y arruinen el Templo y la nación) el cual, significativanente está dicho en una sesión del Sanedrin ( $v .47$ ) y con un comentario irónico del que parece que Juan no se pudo contener. Y luego el de 19,16: "no tenemos más rey que a César." 'rase bien impresionante para ser puesta en boca de un judio y que, también significativamente, está dicha nada menos que por los "sumos sacerdotes." Por supuesto es muy poco probable que unos personajes como los sumos sacerdotes dijeran históricamente una frase asi de clara y de explicita. Pero es en cambio muy coherente mirar esa frase como un desenmascaramiento de qué es lo que habia realmente debajo del argumento piadoso e impecable de los judios: "tenemos una ley y según la ley debe morir, porque se hizo Hijo de Dios" (19,7). Ese argumento que suena ran correcto es en realidad ideológico en el sentido marxista del término (es decir: enmascaraba una mentira) y Juan muestra que sólo teniendo por rey a César se puede argùir así ante Jesús; y lo muestra "obligando" narrativamente a los Jefes a exhibir cuál es el fondo de la verdad que esgrimia el pueblo como argumento en 19,7. En este sentido yo sostendria que el cuarto evangelio se puede comparar al Capiral de Marx, en cuanto a esta intención bien concreta: es el intento de desenmascarar una ideología justificadora de la opresión. En el caso de Marx la opresión capitalista que se presenta como justa, humana y libre. Y en el caso de Juan la opresión de los que vivían celosos de su propio poder, que en realidad no era más que el poder de Roma, y que se presentaban como cumpliendo la voluntad de Dios y como viniendo de Dios, mientras que Jesús en cambio - para ellosno vendrá de Dios, sino que será pecador $(9,24)$, como lo son para cualquier sistema todos los que lo combaten, aunque no combatan a Dios.

Creo que esta denuncia de los aprovechados del poder de Roma y camufladores de ese aprovechamiento con el nombre de Dios, no debe dejarse fuera del cuarto evangelio, aunque luego sea claro que, a éste, el luchar contra Roma no le importe nada porque ni históricamente era eso posible en la época en que se escribe, ni teológicamente cree en una liberación intrahistórica exterior a la comunidad (el reino no es de este mundo). Pero precisamente porque el evangelio de Juan consiste en ese juicio (los judios no podian creer porque vivían practicando la injusticia en su amor a su propio poder), es por lo que culmina con esta frase que es una de las más importantes y más serias de todo el Nuevo Testamento: "si estuvieran ciegos no tendrían pecado, pero como dicen que ven su pecado persiste" $(9,41)$. Esta frase me parece como la cumbre del sendero que anunciaba el prólogo: las tinieblas quieren "sofocar la luz" o "los suyos no lo recibieron." Y desde esa cumbre se desciende ya hasta el terre- 
no práclico y concreto de 19,36 que hemos cilado: no tenemos inás rey que a César. Esto es exactamenle lo que hacen quienes dicen que ven; en este cvangelio son llevados a reconocer cuál es su verdadero rey. La parál'rasis minuciosa de la [rase es difícil porque se escapa como un pez entre las manos; pero más o menos diría así: si estuvieran ciegos, tropezarian (es decir; obrarian el mal) por su ceguera; y eso seria excusable porque el ciego no puede distinguir tinieblas y luz. Pero cuando pretenden que no estál ciegos, afïrman que si, que distinguen entre tinieblas y luz y, por lo tanto, si van a las tinieblas y Iropiezan (obran el mal) ya no puede ser por falta de luz, sino por odio a la lus, es decir, no porque no vean, sino porque aman a las linieblas más que a la luz.

Sinceramente, conozco pocas palabras que resulten más crilicas para la injusticia del mundo moderno, ni concepción más clara de que esa injusticia tiene que impedir o falsificar la fe en Dios. Y, por supuesto, estas palabras no se refieren sólo al mundo moderno ni sólo al sistema religioso judio: afectan tambièn a los detentadores de cualquier poder religioso si, ante el hombre que se libera, que comienza a ver, o deja de pedir limosna, creen poder afirmar que aquello es contrario a Dios porque no les respeta los sábados de ellos ( $\mathrm{J} 11.5,10$ y 9.14) o les quita público a ellos $(7,31.32$ y 46,48) o crea problemas a su prestigio $(9,24.25$ y $29-34)$ o les hace sentir a ellos la amenaza de que puedan venir "los romanos" $(11,48)$ : "como dicen que tienen magisterio, su pecado persiste." Realmente, tras la muerte de Jesús se vuelve casi única verdad que Jesús vino "para un juicio:" para que los que "ven" con esa razón que maló a Jesús, se vuelvan ciegos; y los que estaban ciegos, de acuerdo con la razón de este mundo, vean. Y con este último "ver," estamos otra vez en la le con la que comenzó nuestra exposición, y hemos cerrado el circulo: después de la muerteresurrección de Jesús queda la fe, lo cual significa ahora mucho más que al comienzo de este apartado.

\section{Conclusión de la primera parte}

El objetivo de cuanto llevamos dicho hasla ahora no es entablar una discusión exegética sobre el cuarto evangelio, sino - por asi decir- "tranquilizar" a quienes se asustan cuando oyen que la verdad cristiana tiene un criterio "práxico" y situacional de verificación, temiendo que en esa afirmación haya una desnaturalización de la ortodoxia. A éstos hemos de decirles que lal afirmación es por el contrario enormemente biblica, y que la radical falsificación de la ortodoxia (que hoy nos amenaza particularmente) sería desconocer esta verdad incomoda. Para mostrar esto nos hemos limitado a evocar algo que se había dicho desde siempre: que el cristianismo es una vida antes que una doctrina y que esta era una enseñanza fundamental de los escrilos joánicos.

Pero podemos evocar que tambièn se ha defendido siempre en la tradición teológica la posibilidad de un cristianismo "anónimo" (sin discutir ahora sobre el nombre) o de una fe "implicita," precisamente porque puede haber una vida que merezca el nombre de cristiana (hasta el extremo de llegar a ser "justificante"), aunque no profese unas "verdades expresas" cristianas. Y como último ejemplo quiero citar aún otro dato biblico en el que hoy parecen 
coincidir los exegetas, y que toca algo tan esencial en la fe cristiana como es el monoteísmo.

Históricamente hablando, la revelación de la verdad monoteísta es el resullado de una praxis, de un vivir monoteisla. Israel, en principio, acepta otros dioses de otros pueblos, pero se prohíbe servirles: de modo que podemos decir que sólo para la praxis de Israel Yah̆vé era el único. En estos momentos, la contienda con los otros dioses se basa todavia en que "no te darán tanto como Yahvé" y en que "Yahvé es un Dios celoso." Esta vida de fidelidad es la que lleva a la verdadera doctrina: Yahvé es el único en absoluto y (por eso) el creador de todo. La contienda con olros dioses se basa ahora en que "son obra de manos humanas" y por tanto nada; es decir, no sólo no son creadores, sino que son... creaturas del hombre. ${ }^{6}$ La revelación del monoteismo precisamente a partir de la praxis de fidelidad de Israel, es uno de los casos más privilegiados (por Iratarse de algo tan central a la fe cristiana) en los que la praxis aparece como criterio de verdad, y la verdad cristiana como algo que debe ser realizado antes que "sabido." La Iglesia pues no debe rehuir este principio de la praxis como crilerio de verdad como si fuese una contaminación marxista de ésas que tanto parece temer; aunque haya que conceder tranquilamente que ese principio asi enunciado es sólo la mitad de un círculo, que debe cerrarse para quedar completo. Antes que ser "marxista" ese principio ha sido algo tan biblico que a él debe su ser la misma Iglesia.

Y si con esto hemos logrado eliminar los recelos sobre el elemento práxico y situacional de la verdad cristiana, estamos ya preparados para mostrar la importancia actual del pobre como lugar teológico, y de la opción por el pobre como contenido de esa praxis veri-ficante.

\section{LA REVELACION DEL POBRE}

\section{El pobre como “theologia crucis” (1 Cor. 1)}

Al citar en latín la expresión theologia crucis queremos presentarla como expresamente vinculada a su acuñación luterana. Queremos decir con ello que el pobre no es lugar teológico en el sentido teofánico de una theologia gloriae, sino en el sentido creyente de una teologia de la cruz. En Lutero, como ya saben los entendidos, la teologia de la cruz no tiene nada que ver con la práctica del sacrificio, la abnegación o la ascética, sino que tiene que ver pura y simplemente con el conocimiento de Dios. Sostiene que al verdadero Dios, al Dios revelado en Jesucristo, no se le conoce por la vía epifánica de la demostración racional, sino que sólo se le reconoce por la vía inesperada de la escucha obediente. Dejando estar ahora las posibles exageraciones exclusivistas con que Lutero sello su teoria, es preciso reconocer que con ella se ejerce una crítica absolutamente válida contra todo afán de un conocimiento curioso u orgulloso de Dios, que va a dar siempre en un ídolo. Y, por tanto, hay que conceder que la theologia crucis es, por lo menos, si no el camino único, sí un criterio negativo permanente para el conocimiento de Dios. Como tal criterio negativo revela además la protesta perenne de Dios contra el orgullo totalitario de la razón hu- 
mana. El problema último de la re no es si hay camino o no para que el hombre encuentre a Dios. $\mathrm{O}$, al menos, no es exclusivamente ése, sino también éste otro: si a Dios hay que buscarlo donde El quiere revelarse o donde juzga el hombre que debería o le gustaría encontrarlo.

Esta contextualización nos suministra un primer elemento importante para hablar del pobre como lugar teológico. Al hablar asi, de ningún modo se quiere convertir al pobre en una epifania de dios, en una manilestación del misterio "fascinante y tremendo." Con lenguaje más gráfico: el pobre no pertenece a las leofanias del Antiguo Testamento, sino a la cruz del Nuevo. Y esın implica una primera conclusión: el pobre no es lugar teologico porque "convence" o "hace ver," sino porque desinstala $y$, en lodo caso, hace creer y hace obedecer.

Puede concederse sin dificultad que, en el nivel de lo expresamente subrayado, esto no siempre ha sido dicho por los teólogos sudamericanos con la insistencia machacona con que lo estamos diciendo ahora. Pero es preciso añadir que, si no se decia así, es porque, desde la brutal experiencia de lo que es el pobre y de lo que es la opresion, podía darse por supuesto. El problema de un malentendido ha brotado cuando los latinoamericanos comenzaron a ser leídos por teólogos europeos que no tenian ni remota experiencia del dolor de los condenados de esia tierra: entonces es cuando los subdamericanos han podido ser malentendidos como si hablasen de los pobres desde una theologia gloriae.

Pero entendida como theologia crucis, la afirmación del pobre como lugar teológico no puede ser acusada de efectuar ninguna canonización de los pobres en la dirección marxista del universal negativo, ni puede ser acusada de legitimar teológicamente un proyecto político. No. El rostro del pobre no lleva ninguna inscripción luminosa que diga in hoc signo vinces y que se pueda poner en algún lábaro antes del combate. Otra cosa muy distinta de legitimar teológicamente un proyecto político es la afirmación de que los pobres como lugar teológico han de crearle a la Iglesia una gran sacudida y un temor que son, en definitiva, políticos, puesto que el pobre no es hoy sólo un individuo o serie de individuos aislados, sino también una clase o conjunto de clases sociales. ${ }^{8}$ Tampoco se puede decir - como ha escrito alguien a propósito de Jon Sobrino- que expresiones como "los pobres sacramento de Cristo" o "los pobres constituyentes de la lglesia que es, por eso, Iglesia de los pobres," u otras parecidas, sean necesariamente "de claro sabor donatista. " $A$ " Pues esto equivaldria a aceplar que también la expresión "Iglesia de la cruz" es de sabor donatista, o que la afirmación "'santa Iglesia" es igualmente donatista. Los pobres pueden ser pecadores, pero esto no significa que no son lugar teologico. Y permitaseme formular esto de una manera bien provocativa, pero que resulta muy pedagógica en el contexto de este artículo: los pobres pueden ser tan pecadores como ha podido serlo la Iglesia institucional o la Iglesia romana (;lo han sido terriblemente en algunos momentos de su historia!). Pero, al igual que a la Iglesia la seguimos llamando santa a pesar de su pecado, los pobres siguen siendo "lugar teológico" porque ellos no son lugar teologico por su inocencia, sino por su pobreza. 
El elemento revelador no está,pues en la entidad del pobre, sino en lo que a traves del pobre me dice y me comunica Dios que, al revelarse, escoge lo débil del mundo para confundir a lo luerte. Y a esta meta vamos a intentar acercarnos antes de cerrar el presente apartado, ahora que ya tenemos despejado el camino para llegar a esa revelación: al igual que la cruz, el pobre revela porque desinstala. Y como desinstalador ha de ser acogido en paciencia, salida de si y conversión obediente que, luego de la aceptación del pobre, se convierten en rebeldia y protesta; la misma protesta que hace Dios y que acoge Dios.

La protesta que hace Dios. Es un axioma teológico que la cruz de Jesús es reveladora del pecado del mundo. Y desde Mt. 25,31ss, este mismo axioma tiene aplicación a los pobres. En ellos efectivamente se aprende algo que no dice ningún libro ni ciencia alguna: que la mirada de Dios sobre este mundo es una mirada doliente. Y tambićn la mirada de Dios sobrc esıa Iglesia, su pueblo de dura cerviz, que tiene en este punto los mismos o mayores pecados que los gentiles. Porque ninguno de los dos desea comprometerse a acabar con el dolor de los pobres, si el precio para ello es renunciar a toda politica de autoafirmación. Quizás sea esta renuncia lo que Bohoeffer llamaba "estar con Dios en su pasión." Mientras que las otras espiritualidades y teologias cometen el pecado que el poeta formuló con tanta lucidez:

No puedo querer ni quiero

a ese Jesús del madero,

sino al que anduvo en la mar...

Porque en un mundo en el que ya es posible acabar con (o al menos reducir muy sustancialmente) los tonos espeluznantes que ha adquirido la pobreza, ${ }^{10}$ en un mundo donde, por consiguiente, los pobres ya no son simplemente pobres, sino empobrecidos, y donde, por tanto, la potreza ya no es meramente desgracia, sino injusticia, en un mundo asi, no es posible milar al pobre sin decir "Padre, he pecado" (Lc. 15,21), o cerrarse pecaminosamente sobre si. Y ese decir Pater peccavi es para toda la tradición cristiana, desde la carta a los Romanos, presupuesto necesario para conocer a Dios. ${ }^{\prime \prime}$

La protesıa que Dios acoge. El lugar teológico no revela, pues las profundidades del ser de Dios inaccesibles tanto a la soberbia como a la curiosidad humanas. Revela la "economia" (o el plan salvador) de Dios, en el cual se transparenta con verdad divina el ser de Dios como amor. De acuerdo con esto hemos de decir que el lugar teológico es, antes que nada revelador de la volunlad de Dios. Y la voluntad de Dios es "misericordia quiero y no sacrificio" (M1. 9,13 y 12,7). Mientras que la voluntad del hombre - también del hombre de Iglesia - suele ser esla olra, conténtate con nuestros sacrificios y dejanos en paz con tus misericordias". Quiero retomar aqui un rasgo muy característico (y muy olvidado) de la teologia de Ignacio de Loyola, para quien el único camino hacia el conocimiento de Dios parece ser el conocimiento y cumplimiento concreto de Su Voluntad. ${ }^{12}$ Conocimiento y cumplimiento que parecen requerir, además de toda clase de medios humanos, una paciencia infinita y tranquila, reflejada en la lentitud de la trayectoria dcl santo, como también se habia reflejado en la lentitud de la trayectoria de Abraham. Todo esto vuelve a 
empalmar con el principio neotestamentario de que al creer precede un "obrar," que no es de "obras de la ley," por supuesto.

Resumamos pues este primer apartado. Al igual que la luz de Jesús, el pobre no revela a Dios por su naturaleza teofánica, sino por lo que desinstala al hombre. Esta revelación se concreta en dos puntos: el pobre como revelacion del juicio de Dios que es un juicio de condena sobre este orden presente ("este mundo") y el pobre como revelación de la voluntad de Dios que es voluntad salvadora. Pero, con esta última frase, hemos llegado al segundo de los capitulos que antes enunciábamos, en la voluntad de Dios se revela el Gran Pobre que es el Amor.

\section{El pobre como revelador del amor pobre (Mt. 25,31ss)}

La cruz no revelaría a Dios del mismo modo si Jesús hubiera sido colgado de ella por alguna fatalidad natural o por su propio a fán de ser héroe. La cruz revela a Dios porque el crucificado es crucificado por alguien y por algún motivo concreto de ese alguien. La cruz es pues un vocablo que, teologicamente hablando, tiene siempre un correlato, a saber, los crucificantes. Y esto lo revelan a maravilla los pobres, cuando los padres de la lglesia dicen que ellos son tales por los ricos. El paralelismo con Jesús se hace más estrecho porque también los que crucificaron al nazareno podian decir que hubiesen preferido no tener que hacerlo;. no eran en este sentido asesinos "formales," si es que el asesino es aquel que mata por matar. Ellos sólo pretendian mantenerse, sobrevivir en su puesto de privilegio. No es, pues, el sadismo o la maldad confesada, sino el mecanismo de una falsa autodefensa y autoestima, lo que llevó a los crucificantes a levantar la cruz, y lo que lleva a los ricos a producir pobres. ${ }^{13}$

Pero, cuando al hombre se le revela esta "mentira" (Jn, 8,44; Rom. 1,25) este mecanismo más sutil que, al ser evidenciado, deja fuera de juego todas las excusas, entonces no queda más remedio que reconocer que los que neutralmente llamamos "pobres" son en realidad los empobrecidos, es decir, que los pobres no pertenecen hoy al plan de Dios, sino a la obra de los hombres. 14 Reconocer eso es la conversión, es un cambio equivalente a la "caida del caballo" del perseguidor Pablo. Y esa caída del caballo implica también "reconocer al Señor como perseguido;" porque Pablo tampoco pretendia matar, sino defender al judaísmo; pero al dejar de matar reconoce al Señor: "yo soy Jesús a quien tú persigues" (Hchs. 9,5). Vale la pena notar como en la tradición cristiana Martín de Tours parte su capa para compartirla con el pobre, y aquella noche sueña que ve a Cristo vestido con la mitad de su capa de soldado romano. El carácter revelador del gesto adquiere un relieve tal que, en adelante, todas las iglesias de la Galia se decoran con esa media capa roja, la cual simboliza inequivocamente cuál es el verdadero "lugar de Dios." Tanto que de esa capa deriva nuestra palabra capilla que ha venido a ser sinónimo de iglesia o templo. En la capa compartida mora Dios.

Por eso, al revelar a los crucificantes, los pobres revelan también la debilidad de Dios, es decir, revelan que el hombre tiene poder para crucificar a Dios, o que Dios ha abdicado de su fuerza ante el hombre y por amor a la libertad 
del hombre. Este es uno de los puntos más escandalosos de la revelación judeocristiana, también para el hombre de hoy quien, a pesar de su talante secular y tecnocrático (o quizás precisamente por ell), sigue pensando que se las compondría mucho mejor con un Dios que fuese "realmente tal," y por eso resultara "cientificamente" controlable en forma de ajustes de cuentas inmediatos y exactos. Mientras que un Dios que "entrega" a los pobres, como entrego al justo, es algo que desmonta demasiado la capacidad de cálculo, de previsión y de planificación de los sabios, como para que pueda ser tenido en cuenta. Por eso el hombre reaccionará despreciando la idea de scmejante Dios como una mala calentura, y -en el mejor (?) de los casos- buscando otros dioses más "razonables."

Pero he aqui que, en esa misma reacción, no escapará el hombre al acoso de Dios, pues Dios se le revelará como identificado con aquel justo inerme e incómodo y a traves de el, con todos los condenados de la tierra. Es decir, se revelará descubriendole al hombre su increible poder, pero un poder que es también responsabilidad, el poder y la responsabilidad de matar a Dios: "a mi me lo hicieron" (Mt. 25,40). Dios se revela como débil porque su ser es el amor (Jn. $4,16)$ y el amor no liene otra fuerza distinta de la de su misma realidad que, como tal, llama y solicita, pero no fuerza ni impone. La definición de Dios que daba Federico Ozanam: "el Gran Pobre," es el reverso de la medalla de la definición neotestamentaria; Dios es amor. Efectivamente, el amor es el gran pobre.

Y esta definición biblica es la que más incómoda resulta al hombre. Esıe se negará a aceptar ese poder y esa libertad que le dan la definición de Dios como amor, y que son el poder y la libertad de la responsabilidad absoluta. El hombre pretenderá entonces que él nunca ha crucificado a ningún inocente, y menos a Dios; él sólo hace "reajustes" necesarios, "Mexibilizaciones" progresistas, "justicias" apaciguadoras, "medidas" útiles para que el pueblo viva $(J n .11,50)$. Pero he aqui que en toda esta cháchara verbal hay una palabra -una sola- que no es posible borrar: las víctimas. Las víctimas están ahí, con ese nombre desesperante, como las manchas de sangre en las manos de lady Macbeth: tenaces, inacallables, omnipresentes $u$ omnipresentidas, como un ruido sordo e ineliminable que empaña una iluminación preparada para resultar fastuosa y efectista y deslumbrante. Tanto que la experiencia de la percepción de las víctimas no es necesariamente religiosa, cualquier hombre, aunque no sea creyente, puede hacerla; y T. Adorno la ha expresado de forma insuperable:

Después de Auschwitz, la sensibilidad no puede menos de ver en toda afirmacion de la positividad de la existencia una charlataneria, una injusticia para con las víctimas, y tiene que rebelarse contra la extracción de un sentido por abstracto que sea, de aquel trágico destino... Auschwitz no habría sido posible sin la frialdad, el principio fundamental de la subjetividad burguesa... Para ser verdadero, el pensamiento tiene, por lo menos hoy, que pensar también contra si mismo... Auschwitz demostró irrefutablemente el fracaso de la cultura... Toda la cultura, después de Auschwitz, 
junto con la crítica contra ella es basura (Dialectica Negativa, 361, 363, 365-67).

Pero esta verdad tan humana se agranda al ser formulada religiosamente: la víctima es Dios. Se agranda y quizás encuentra ahí su única posibilidad de redención. Y por eso no debe perderse de ninguna manera el nombre que la tradición cristiana ha dado a Jesús durante siglos: la víctima. No debe perderse ese nombre aunque necesite ser resituado porque los mismos cristianos se han defendido de él, tratando de desvincular a esa Víctima de las otras víctimas para que no les revelase nada, y para, de ese modo, echar sobre Dios la culpa de esa victimalidad. Hay, pues, que volver a llamar a Jesús Victima, pero sabiendo que no es víctima del Padre, sino nuestra, no víctima que agrada a Dios, sino víctima que necesitamos los hombres; no víctima que Dios "exige" a los hombres, sino victima que Dios "entrega" a los hombres. Entendida así, hay que mantener la palabra víctima porque sirve para sacar al hombre de la mentira y encararlo con esa verdad que se niega a ver: "con vosotros está y no le conocéis; con vosotros está; su nombre es El Señor." Por supuesto que todo es lo podría decirse también en cifras: lo que ha gastado la FAO durante todos sus años de existencia equivale apenas al precio de un solo submarino nuclear, etc. Pero en estos momentos es preciso decirlo teológicamente, porque sólo esla verdad teológica podrá devolver un poco de seriedad al hecho religioso cristiano, abaratado hoy en el primer mundo entre folklores y moralismo, cuando, en realidad, el folklore es una falsificacion que no tiene mucho que ver con la alegria de la fe, y el moralismo es otra falsificación que tiene poco que ver con la exigencia y la responsabilidad de la fe.

Habiamos dicho en el apartado anterior que los pobres son reveladores del carácter "desinstalador" del Dios cristiano. Ahora añadimos que hoy, en cuanto paradigma del oprimido, el pobre como lugar teologico revela la paciencia de Dios que es el correlato de la libertad de los hombres, pero revela también la misericordia férrea de Dios. Esta segunda consideración se unifica ahora con la anterior y la interpreta: el que a Dios sólo se le encuentra en la cruz no es un enunciado nocional (como si la cruz fuese un concepto) sino práxico: a Dios no se le encuentra en la praxis egoista de los corintios, sino en la superación de sus divisiones (Pablo); no se le encuentra en la praxis farisaica e hipócrita de los monseñores del Renacimiento, sino en la actitud del que se reconoce necesitado de perdón (Lutero). Y finalmente no se le encuentra en la pra$x$ is insolidaria e individualista de los ricos, sino en la entrega de sus riquezas al servicio de los pobres. Ahi brilla la misericordia de Dios que sigue apelando a la responsabilidad y resulta juicio para la falta de responsabilidad del hombre. Pero con esta alusión a la misericordia llegamos al tercero de los capitulos anunciados: la misericordia férrea es la gloria de Dios.

\section{El pobre como revelador de la gloria de Dios (1 Jn. 4,20b)}

Si hasta ahora el pobre como lugar teológico parecia empobrecernos porque desinstala al creyente y al teólogo, y porque desmarca a Dios de las expectativas humanas a que pretendemos someterlo incondicionalmente, ahora, en 
este apartado, se revela en el pobre "la sabiduria de Dios y la luerza de Dios para nosotros que hemos creido" (1 Cor. 1,24): el hombres descubre que oplar por el pobre es su verdadera riqueza. Puesto que e! empobrecimiento de Dios no es por amor a la pobreza, sino por amor a los pobres y para que "su pobreza nos enriquezca" ( 2 Cor. 8,9$)$, Dios se revela en los pobres no simplemente identificado con ellos, sino identificado con su causa: convirtiendo en real esa vaga promesa de la negalividad, y acogiendo como suelo fértil las raices que harán nacer y crecer la esperanza para los pobres (cf. MI. 11,2ss.). La gloria de Dios es que el pobre viva, la voluntad de Dios es que el reino llegue, y, por eso, descubrir a los pobres como lugar reológico no puede hacerse sin "optar" por ellos y asumir su causa.

Asumir la causa del pobre como sacramento del reino de Dios, de la causa de Dios y de la paternidad de Dios, es condición de posibilidad para todo "logos" sobre Dios que no esté demasiado hecho "a imagen y semejanza" del sujeto, y que por eso quede como "tocado" ante la sospecha feucrbachiana de ser una pura proyección de los deseos del sujeto. Pero asumir la causa implica una dosis de cercania y de asimilación a los pobres. Dosis imprecisable porque no es una obra de la ley, pero dosis innegable porque es un frulo del Espiritu. $Y$ si los pobres son efecto de los empobrecedores - como antes veiamos-entonces la causa de los pobres es necesariamente contraria a la causa de los ricos, que es el seguir empobreciendo, y que acaba por oscurecer la verdad de Dios, porque borra su paternidad, su Justicia y su misericordia. En este sentido, hay que afirmar que la opción por los pobres no es excluyente de los ricos, pero si que lo es de la causa de los ricos. No es por tanto "cuanlitalivamente" excluyente, porque también el rico está llamado a ella, pero si que lo es, por así decir, "cualitativamente:" porque de esa opción queda excluida la riqueza en cuanto empobrecedora, en cuanto insolidaria y en cuanto concebida como apropiación y no como administración de lo ajeno, por usar un lenguaje muy querido a los padres de la Iglesia.

Asumida esta causa del pobre se irá viendo cumplida en ella la que quizás es ley [undamental de la presencia y de la manifestación de Dios entre nosotros: Dios se hace presente alli donde lo no-humano llega a convertirse en humano, de acuerdo con la visión de lo humano que tiene Dios; porque el hombre, al vivir en la mentira, también es capaz de llamar humano a su misma falta de humanidad. Y lo no-humano, en este mundo nuestro, es por un lado la in rrahumanidad del pobre, a quien la atroz falta de condiciones impide el más elemental desarrollo de su humanidad, y, por otro lado, la inhumanidad del rico, cuya insolidaridad y cerrazón sobre si pervierten todas sus realizaciones humanas. La infrahumanidad del pobre que muchas veces genera antihumanidad y odio, y la inhumanidad del rico que casi siempre genera falsa humanidad. Dios se hace presente por tanto alli donde "aparece la humanidad de Dios" (Tito 3,4) como ocurrió privilegiadamente en Jesús de Nazaret, e irradia desde El a toda la historia.

La gloria de Dios es que el pobre vive, decía Mons. Romero. En la Iglesia se reza y se canta cada día muchas veces aquello de "gloria al Padre y al Hijo y al Espiritu Santo." Pero lo que da gloria al Padre y al Hijo y al Espiritu Santo 
no es que cantemos eso, ni aunque al hacerlo inclinemos profundamente la cabeza. Lo que da gloria al Padre es que el pobre sea reconocido en el Hijo como hijo suyo, y que podamos reconocer eso gracias al Espiritu. El canto o el rezo de Gloria Patri, sólo vale en cuanto que lo cantamos haciéndonos conscientes de eso, y en cuanto nos impulsa a dar a Dios esa gloria.

Y esa gloria de Dios está ya presente, trabajando al pobre. Precisamente por eso, porque está ya presente, es por lo que la causa de los pobres puede ser vista en un proyecto histórico. Jesús no sólo anunciaba que el reino de Dios será -en un futuro- de los pobres, sino que, ya ahora les han sido revelados secretos del reino que están ocultos a los ricos y sabios (cf. Lc. 10,21). Tocamos aqui uno de los puntos más vidriosos del tema, porque tiene los riesgos que comentábamos al conienzo de todo este escrito; el riesgo de alguna mitificación del pobre, sea de carácter marxista o donatista, o simplemente idealista o ingenua. Ya dijimos entonces que los pobres no son lugar teológico por su santidad o por su transparencia cpilánica, sino por su pobreza. Pero podemos añadir que ese lugar, difícilmente sería teológico si -como ocurre también con la cruz - no acabara por descubrirse en él alguna huella o señal de la presencia de Dios, como la que obligó al centurión romano a exclamar ante el crucificado: verdaderamente este hombre era Hijo de Dios (Mc. 15,39).

$Y$ efectivamente puede ser asi. Pues asi como en aquel pecador que era el publicano de la parábola, la asunción responsable y serena de su pecado, revelaba una humildad que sólo podia ser señal de su justificación ante Dios (ver Lc. $18,13,14)$, así en los pobres, la asunción serena, madura, y solidaria de su causa, en medio de un imperio perseguidor y de unos poderes desesperadamente hostiles, da testimonio de una libertad inexplicable, que se asemeja incluso a la libertad de los primeros inártires cristianos ante sus perseguidores. Y la verdadera libertad siempre es señal de la acción del Espiritu de Dios (2 Cor. 3,17).

Creo que esto es exactamente lo que expresa el siguiente texio, brotado del mundo de los pobres, y que hablará por sí sólo más que mil explicaciones mias. Permitase pues citarlo integramente:

También y sobre todo anunciamos un evangelio, una buena noticia: se puede vivir en la oposicion. No dependemos de la volunlad de nuestros opresores. Podemos desafiliarnos de sus organizaciones, desoir sus slogans, ignorar sus modas, desconocer a sus lideres. Ellos nos decretan la muerte política pero vivimos. Trabajamos en sus lábricas, en sus campos, en sus oficinas, en sus hospilales, en sus escuelas y universidades, pero no como esclavos sino aprendiendo a manejar lo cue un dia será de iodos. Este sistema se nos presentaba como un dios capaz de dar la vida y la muerte. Nos exigia reconocimiento y sumision. Hoy somos ateos de ese dios y seguimos vivos. Esta es nuestra buena noticia: hemos descubierto los límites de este sistema: no es todopoderoso. Más aún: hemos experimentado este nuevo poder como un poder que nos libera del miedo a morir. Por ese miedo pasábamos la vida como esclavos. Ahora sabemos que nuestra fuerza puede enriquecer a otros y que en nuestra debilidad se muestra la fuerza de Dios como salvación para todo el que se atreve a desolidarizarse de es- 
tos poderes de muerte para vivir de nuestra esperanza. ${ }^{15}$

En todo este texto hay una serie de elementos que, si se me entiende bien, me atreveria a calificar como de un franciscanismo "político" o comunitario. Son elementos de la misma experiencia franciscana de la pobreza como liberrad. Libertad frente al "mundo," frente al orden este que somete, domina e impone a través de la esclavitud de la riqueza. Y libertad no sólo personal, sino comunitaria, de clase incluso. Es todo un colectivo social, precisamente el colectivo oprimido, el que puede hacer esta experiencia de libertad: subyugados, pero "no dependientes de la voluntad;" en la opresion, pero "en la oposicion;" supeditados, pero "no como esclavos sino aprendiendo;" dominados, pero "ateos de la idolatría de este sistema;" empujados a la muerte, pero vivos y "con un poder que nos libera del miedo a morir..." Esta buena noticia que empieza por devolver la libertad al pobre ya eu su empobrecimiento, y como anticipo de su liberacion, es la que permite retormar el lenguaje de Francisco sobre la pobreza como hermana y señora. Y esta experiencia es la que alimenta la esperanza en un futuro que no estará hecho solamente de una inversión de poderes que mantenga los mismos criterios, los mismos valores y los mismos dioses, ${ }^{16}$ sino que será un futuro del comparlir sobre el tener y del ser sobre el poseer. Que los pobres son lugar privilegiado para la captación de esos valores lo ha defendido la tradición cristiana sin caer por eso ni en la mitificación ingenua ni en el donatismo teológico: "por esto dice san Agustín -escribia hace siglos Francisco de Osuma- que es más seguro del amor entre los pobres que entre los ricos, y por esto los grandes señores nunca son entre si buenos amigos, y entre los pobres la caridad añade en amor lo que falta en las riquezas." "17

Y desde aqui, la frase que engloba este apartado sobre el pobre como gloria de Dios, recibe la misma aclaración que recibia en su autor original Ireneo de Lyon. Cuando san Ireneo escribe gloria Dei vivens homo, añade que la vida del hombre es Dios, es decir, no su propia autoafirmacion. Igualmente ahora, tras parafrasear gloria Dei vivens pauper, podemos añadir que la vida del pobre no es el enriquecimiento, sino el compartir, la solidaridad. La vida del pobre y la vida del hombre.

Resumamos también este apartado, la gloria de Dios es que el pobre viva, porque Dios se hace presente en la humanización de lo no-humano. Humanización según Dios, hemos dicho, y cabe añadir que eso equivale a humanización según lo mejor del hombre. Pero esa gloria de Dios es el hombre el llamado a dársela, amando al pobre como Dios le ama, es decir, asumiendo su causa y transparentando asl a Dios.

Y la desinstalación de la cruz, la interpelación del Amor Pobre y la gloria de Dios en el pobre, nos permiten ahora resumir todo este apartado diciendo una palabra que unifica todas sus partes en aquel punto que es el central y casi el primario de todo discurso sobre Dios: el tema de su transcendencia y/o inmanencia. 


\section{Conclusión: el pobre como "Irascendencia-inmanencia" de Dios}

La religiosidad humana espontámea busca un Dios enya santiclad sea lejania, trascendencia. Hay algo válido y necesario en este modo de concebir: si el hombre no esıá muy percalado de la trascendencia y de la lejania e inasequibilidad de Dios (e incluso aunque lo esté), la relacion del hombre con Dios se convierle en idolatria, o en manipulación de Dios. La santidad de Dios intenta por tanto asegurar el respelo del hombre a Dios, y por eso el Levílico escribe: "scan sallos porcule yo Yahvé soy sallo" (20,26), con una concep)ción de la santidad de Dios muy en la linea del apartamiento, la pureza, la nocontaminación, elc.

Pero -esta es la trágica ambigüedad de codo lo humano - lambién de esla forma de concebir se adueña el pecado del hombre. Pues la lejania de Dios lleva implicita la aceptación de mediaciones y, a la larga, el mediador se convierle en un privilegiado que acapara poderes (converiidos ahora en reales y cercanos) de ese Dios que ha quedado tan lejos: el sacerdocio sc convierte cлtonces (y ha sido asi siempre, fatalmente) en una casta de privilegiados, con dcrechos únicos, en un factor de desigualdad, y en ocasión de una ruptura de la fraternidad en aras de una "paternidad" que en realidad ha sido arrebatada a Dios para autoasignársela el hombre. No es casualidad por eso si Jesús dice (an) tajantemente, a nadie llamen padre en la lierra (Mi. 23,9). Y no negamos con esto que puede haber excepcionalmente designaciones de paternidad que no la arrebalan a Dios, sino que confiesan una paternidad como sacramento o Iransparencia de la palernidad de Dios. Pero, a la larga, el deslino Irágico de esle lenguaje será el otro, y por eso Jesús lo prohíbe aunque nosotros no le hayamos hecho caso. Como tambièn con Jesús se quiebra el tipo de sacerdocio que acabamos de criticar, aunque el "ministerio" de la Iglesia de Jesús haya vuelto a recaer bastante en él. ${ }^{18}$

Y la razón de esta conducta de Jesús es la siguiente. En Jesucristo se revela un Dios que es, sí, santo y trascendente, pero cuya santidad no consiste en su lejania -en el sentido religioso o metafísico del término- sino más bien en su "locura" (1Cor. 1,13): no está nada cercano estando precisamente muy ccrca; porque está en aquéllos de quienes nosotros nos alejamos, o de quienes nos aleja nuestra falıa de misericordia. Es sorprendente el hecho de que el evangelista Lucas relea la frase cilada del Levilico de esia otra manera: sean misericordiosos como su Padre...etc. La santiclad de Dios, su Iranscenclencia, no es entonces su lejania, sino su misericordia. ${ }^{19}$ Su distancia respecto de nosotros es nuestra falta de misericordia, y esta distancia es aún mayor que la de nuestro carácter contingente respecto del absoluto. Esto es lo que nos revela cl pobre, en nuestra misma falta de capacidad para saber qué hacer con cl.

El pobre es la revelación de esta trascendencia de Dios. De ahi que, si la teología no está situada en la óptica de los pobres de la lierra, si no se hace desde ahí, recae siempre en el Dios del culto frente al Dios de los profelas, y deja de escuchar al Dios que le dice "no quiero sus ofrendas," recae en el Dios del sacrificio frente al Dios de la misericordia, y deja de escuchar al Dios que le di- 
ce. "misericordia quiero y no sacrificio." Recae en el Dios del comino y de la menta frente al Dios del juicio justo, y deja de escuchar a Jesús cuando le dice "esto era lo que habia que hacer." Recac en fin en el Dios de "una noción religiosa general de Dios," frente al Dios del cristianismo. Con eso se aleja la ieologia de Jesús, y por eso le es tan difícil a la teologia moderna integrar la práctica de Jesuis: más cómodo le resulta decir que no sabemos lo suficiente de clla...

$Y$ es que el hombre se ha resistido siempre a aceptar esta revelación, incluso despues de Jesús. La astimaña del hombre ha sido siempre esgrimir la lejania de la santidad abstracta, contra la cercania/lejania de la misericordia. Para Iranquilizar la conciencia, se retoma luego la misericordia como un simple precepto derivado. ético, que no afecta al ser, sino al deber ser o al obrar. Pero el proceso creyente es el contrario, la santidad ontológica de Dios aparece como su misericordia. Antes que nada, Dios es amor ( $1 \mathrm{Jn} .4,16)$ y misericordia liel (Ex. 34,6): en estas definiciones se halla la mayor distancia de la Hiblia respecio de toda la literatura religiosa universal. Sólo después, luego de esta conversión a los pobres y de este encuentro de Dios en ellos, liene lugar la recuperación de la otra clave de la distancia e inapresabilidad de Dios. Esta otra clave sigue siendo absolutamente necesaria para purificar la conversión al pobre (ique el hombre lambién podria acabar desviándola en provecho propio!). Y, por asi decirlo, esta otra clave se visibiliza en la decepción, el fracaso, la desposesión que experimentan en su lucha casi lodos los que creen haber oprado por los pobres, y que llevará, de uno u otro modo, a decir en algún momento: Dios mio ipor que me has abandonado?... Pero si eso se dice como Jesús, abandonándose a su vez. hacia las manos del Padre, ahi se alirma la verdadera trascendencia de Dios.

Asi pues, en la primera concepción de la trascendencia de Dios, la santidad es tan abrasadora que nadie puede acercarse a Dios sin morir. De ahi la importancia de los intermediarios. Dios da miedo, impone. Pero curiosamente, esta concepción acaba perdiendo la trascendencia de Dios que queria salvar, pues el ritualismo, o la mentalidad de que los sacrificios "agradan" a Dios y son de suave olor para $\mathrm{El}$, resultan evidentemente el mayor atentado a la santidad de Dios, hecho como modo de "hacerse valer" del sacerdote.

En la segunda concepción lambién muere el que se acerca a Dios; muere como Jesús porque el que se acerca al pobre es quirado de en medio. Pero esa es una muerte que da vida, y que no pierde la vida $(\mathrm{Jn}, 10,13)$. Y esta es la diferencia. El que se acerca a Dios muere, no deshecho por Dios, sino destruido por los hombres. Aqui está el escándalo de las profecias de la pasión; no en si son o no del Jesús histórico, sino en que éste afirme que $\mathrm{El}$, el justo, el Hombre, va a morir a manos de los hombres. ${ }^{20}$

Al contraponer estas dos concepciones religiosas, no querriamos converlirlas en excluyentes o dilemáticas. La gran audacia cristiana, por ejemplo de la carta a los Hebreos, es confesar en Jesús la confluencia de ambas. Pero para que esto sea posible hay que comenzar por la segunda y, desde ella, recuperar la primera. Comenzando por la primera, el hombre nunca llega hasta la segun- 
da; o, a lo más llegará a ella como imperativo ético derivado, nunca como formulación teológica. Entonces no quedará más remedio que decir que fenómenos como la teología de la liberación, elc., son "pésima teologia" porque impiden al hombre esa contemplación pretendidamente pura de las esencias trascendentes. Pero mucho me temo que quien asi habla no necesita que se le condene porque él se condena a si mismo (cf. Jn. 3,18).

\section{LA REVELACION DEL HOMBRE}

Todo lo anterior es lo que nos hemos atreside a califical - no se vi irrespeluosamente, pero si con un alän de respuesta al evangelio- como "revelación del pobre" o revelacion de Dios en los pobres. Pero hay un triterio que puede ayudar a verilicar esa calilicacion. Se ha dicho con cerdad que lodo hablar sobre Dios es un liablar sobre el hombre. Y esto no lielle por qué entenderse en un sentido reductor a lo Feuerbaith, sino que puede entenderse en el sentido que la leologia llama "económico," es decir, porque Dios se revela a si mismo como Dios en su proyecto de salvación y en su obra de salvación para los hombres. En lo qui dice al hombre sobre el hombre, el hablar acerca de Dios muesıra sus virtualidades, dada la inefabilidad del misterio de Dios aun en el seno mismo de su revelación. Por eso no queremos concluir este trabajo sin trasladar cuanto llevamos dicho al campo de la antropologia coológica. Y para ello elegimos dos puntos. El primero más intrateologico y referido al tema central de la anıropologia cristiana, el de la "justificación" del hombre por la re. El segundo más ad exrra, referido al quehacer global de diálogo de la reologia con la cultura moderna y, en concreto, con la menialidad de la llusiración y sus problemas. Rápidamente diremos una palabra sobre cada uno de eslos dos puntos.

\section{Opción por los pobres y justificación por la fe}

Efectivamente, la caracterización del pobre como lugar teológico queda notablemente reforzada si se considera cómo incide en ese punto central de todo el mensaje cristiano sobre el hombre, al cual con lenguaje paulino, suele calificarse como “justificación por la fe." Tal lenguaje no es demasiado comprensible hoy, con el riesgo enorme de que, por lo oscuro del lenguaje, se pierda lo central del mensaje. Por ello vamos a comenzar aclarando que el problema central del hombre es el problema de la autoafirmación. Que el centro del mensaje cristiano sobre este punto es la autoafirmación por la fe. Y que ese núcleo cristiano desautoriza los dos intentos clásicos de afirmación del hombre: el de la auloafirmación "por si mismo," es decir, por la afirmación y realización de los propios deseos que son los que dician lo bueno y lo malo para el hombre; y el de la autoafirmación "por las obras," es decir, por la honorabilidad del propio obrar bien, que da al hombre motivo para gloriarse. Según Romanos, el primero es el camino del pagano que hay en nosotros. El segundo es el camino del hombre "serio," o ético y piadoso, que todos llevamos dentro también. Ambos caminos resultan inesperadamente fallidos, pues ambos terminan en una inversión o perversión de lo humano, la cual se manifiesta 
siempre en la afirmación del hombre a costa de los otros hombres y, por tanto, en la dominación del hombre sobre el hombre: bien sea la dominación del explotador, o la del inquisidor, el hecho es que ambos "hacen lo mismo" (Rom. 2,1). Aunque todo esto resulta en mi opinión suficientemente concreto, permitase todavia una aportación bien particular a nuestro tema. La tendencia del rico a mirar sus riquezas como "su mérito," su "justificación" por las obras propias, es una de las tendencias más fuertes del ser humano, como lo muestra la violencia con que los ricos esgrimen ese argumento. Lo que hay en este razonamiento tantas veces escuchado, es mucho más que pura defensa ideológica de lo que se liene; es la defensa de lo que se es o se cree ser. Entregado a esa tendencia el hombre ya nunca tendrá la actitud de le que Romanos propugna. Sólo el amor-oplante por el pobre, el ponerse de su parte, le desiroza esa actitud de justificación por obras, $y$ le salva realmente ex fide

Hecha esta ambientación volvamos a los pobres. Según llevamos dicho, en los pobres se revela el pecado del hombre (puntos 1 y 2 de nuestro apartado 1I) y el amor de Dios (puntos 2 y 3 del mismo apartado Il). Con su sola existencia (no con su santidad ni con su poder, etc.) los pobres revelan una radical inversión de lo humano: ellos son no "el reverso," "2l sino la verdadera cara del tapiz de la historia; ellos son no simplemente "la dialéctica," sino — con menos eufemismos - la contradicción de la Ilustración. 22 Con ello el ser del pobre me revela estas dos cosas: que yo soy pecador ante Dios, "lodos han pecado" (Rom 3,23a), y que como pecador soy ante Dios lo que el pobre es ante los hombres, pura necesidad desvalida, “....y todos están necesitados de la gloria de Dios" (Rom 3,23b). ${ }^{23}$

El pobre revela asi la verdad del hombre. Pero esla verdad del hombre -que este se niega a aceplar como es lógico- no está aún completa, pues hemos visto además que en los pobres se manifestaba el amor de Dios que es su gloria. Y este amor de Dios a los pobres, por ser pobres, revela su amor a nosotros pese a que somos pecadores o "cuando somos pecadores y débiles" (Rom. 5,8 y 6). El hombre recibe aqui una fuente de afirmación de si, el amor que Dios le tiene. Pero esa afirmación sólo podrá recibirla el hombre si se deja amar por Dios; esto parece obvio. Ahora bien, lo única forma para el hombre de dejarse amar por Dios es que ame él al pobre, puesto que el amor de Dios al pobre (que es la fuente del amor de Dios a los pecadores) sólo se actúa y se hace creíble a través de nuestro amor a los pobres (como ya dijimos en el apartado II, 2.). ${ }^{24}$

No hay en todo esto ninguna sutileza argumental, sino sólo la asunción de algo muy repetido en el Nuevo Testamento, a saber, la continuidad entre actitud de Dios con el hombre y actitud del hombre con los demás, "amen como yo los he amado" (Jn. 13,34). O todavía más claro, "perdona nuesıras ofensas como nosolros perdonamos a los que nos ofenden." Esta frase del Padrenuestro incluye la siguiente lectura: trátanos a los pobres que somos nosotros, como nosotros tratamos a los pobres. Y, aunque Jesús nos hace formularla en forma de compromiso (quizás para resultar provocativo y pedagógico), es claro que también para Jesús esta continuidad tiene otra formulación más supli. cante, que podria rezarse asi, ensénanos a perdonar como tú nos perdonas; o 
enséñanos a tratar a los pobres como tú tratas a los pobres que somos nosotros.

De este modo el pobre revela a la vez pecado y justificación del hombre. Y ahora se comprende lo que la opción por los pobres tiene que ver en eso que se llama "justificación por la fe." Esa fe consiste precisamente en estas dos cosas: en aceplar la propia pobreza ante Dios, aceptar que el hombre no tiene nada para conseguir esa autoafirmación que desesperadamente necesita y busca, y en saberse amado por Dios en esa pobreza, recibiendo la afirmación que Dios me da y que es la única fuente válida de "fe en sí mismo" y de experiencia de la propia dignidad. Pero es claro que estas actitudes creyentes no son exclusivamente verticales o inmediatistas; toda la actitud y relacion del hombre con Dios está mediada por los hombres. Y entonces, el aceptar la propia pobreza ante Dios, se sacramentaliza en el aceptarse culpable y deudor ante el pobre. Y el saberse amado por Dios en la propia miseria se sacramentaliza en amar al pobre en su pobreza, como cauce y signo del amor que Dios tiene a los pobres y que me ha manifestado al "justificarme" a mi..$^{25}$

Esta fe justificante resulta, pues que no es meramente nocional. No puede ser un puro juicio informativo y ajeno a la experiencia vital del sujeto. Es fe que es vida $y$, por eso, es praxis. Y entonces da lo mismo decir que la fe sin obras es fe muerta (formulación de la carta de Santiago) o decir que la fe en sí misma es obrante (formulación de Pablo) o que la llegada a la luz de la fe está marcada por las obras (como le hemos hecho decir a Juan). Lo único importante es que, tanto en un caso como en el otro, las obras a las que se alude ya no pueden ser "obras de la ley," obras como motivo de autoafirmación para el hombre. Pues son lógicamente posteriores a esa autoafirmación; son más bien el fruto de ella. Amar al pobre no es entonces una "obra de la ley," de la cual el hombre puede gloriarse o tomarla como motivo de autoafirmación, puesto que ese amor al pobre nace precisamente de la aceptación de que el hombre "no tiene obras," - es pobre-y, no teniéndolas, es aceptado por Dios. Y esto parece quedar avalado por la experiencia más elemental, la cual confirma que dificilmente se puede amar de veras a los pobres y optar de veras por ellos, sin una gran dosis de confianza en "Algo" mayor que uno, innominado e incondicionado pero que, aun percibido así como a través de un espejo, merece más crédito y más confianza que la sabiduria clara y distinta de este orden presente.

Desde aquí, la opción teológica y creyente por los pobres, sin dejar de ser necesariamente operativa y práxica (que esto lo es por definicionn), hace una critica a esa misma opción cuando ésta ha sido hecha como obra de la ley. Exactamente la misma critica que el cristianismo efectúa ante toda ética, y que consiste en desenmascarar su fariseismo secreto. Sólo la justificación por la fe evita que el supuesto profeta o el supuesto justo tomen sus obras como autoafirmación, y que el opresor tenga una aparente excusa para no escuchar al profela en el hecho de sentirse condenado por él. Nadie puede condenar al hermano, ni siquiera cuando lo combate, porque todos han pecado y están privados de la gloria de Dios. Pero a la vez, si lodos (el opresor y el profeta, el pagano y el judio...), todos están hermanados en que Dios los ha amado cuando 
eran pecadores (Rom. 5,8), entonces la no opción por el pobre vuelve inexcusable al opresor ante Dios. ${ }^{26} \mathrm{Y}$ sin cmbargo, esa misma opción no justifica al profeta, ya que sólo brota de esa justificación gratuita recibida de Dios.

Resumamos una vez más. De acuerdo con cuanto llevamos dicho se comprende cómo "el Dios que juslifica al impio" es sólo una versión (dada a través del prisma luterano de la modernidad y de la subjetividad) de la otra formulación más amplia; el Dios que está de parte de los pobres. La cual, a su vez, es lambién una versión (condicionada por el pecudo de la historia) de la otra formulación más ontológica: "el Dios que resucira a los muertos y llama al ser a lo que no es" (Rom. 4,17 ).

\section{El pobre como crítica teológica a la Ilustración}

Lo dicho en este articulo ha llevado a subrayar tanco la mediación del pobre respecio de Dios (Mt, 24,3lss.) como la imposible inmediatez en la relación a Dios (Ial como la formula $1 \mathrm{Jn} .4,20$ ), y el pecado que el hombre puede cometer rechazando estas dos condiciones, para buscar a un Dios que es a la vez "mas razonable" (1Cor. 1) y más "objetivable" o menos trastocador de la subjelividad humana (Jn. 3, 20,21). Un pecado con el que el hombre se rechaza a si mismo, puesto que en esas dos condiciones dichas, tambièn se le revelaba al hombre algo sobre su verdadera humanidad.

Desde aqui se comprende mejor ese leirmotiv tan caracteristico de los evangelios de Jesús: los pobres son los destinatarios privilegiados del evangelio, y este mismo detalle es un criterio de identidad y de verificabilidad del evangelio (Mt. 11,5). No se trata de un simple rasgo de ternura psicológica del hombre Jesús que, por delicadeza, prefirió ir a los pobres. Es que el evangelio, por su misma naturaleza, solo puede ser para ellos. Y si los pobres son los destinalarios reales del evangelio, el verdadero diálogo del evangelio con el mundo moderno tendria que ser hecho por ellos o al menos, desde ellos. Todo otro pretendido diálogo entre fe e increencia, o entre teología y cultura, que no esté hecho asi, volverá necesariamente inseguro al creyente por $\left[^{n-1}= \pm\right.$. ! tantidad. Y por eso éste tenderá a comportarse con la clásica reacción del inseguro; o se verá dominado por el interlocutor, o se volverá -o.tsivo frente a él, como recurso de autodefensa ante est dominio.

A partir de aqui, la opción por el . sbre deja de ser algo exclusivamente teológico, para incidir tambièn en un fenómeno culıural de nuesıros días. La vuelıa al pobre y al mundo de los empobrecidos se inserta en la crilica a esa absolutización y de la subjetividad que ha caracterizado a la "modernidad," 27 y cuya crisis está siendo sentida también a otros niveles.

La afirmación del sujeto ha seguido una extraña trayectoria que comenzó con el cogiro ergo sum y, a través de muchos exıraños y complicados vericuetos, llegó hasta el coito, ergo sum de pasadas pornulopias, o hasta el otro grito de camus; "me rebelo luego existo," para terminar en la incertidumbre misma del sum, a que están llevando muchas de las reacciones últimas del resignado morador de occidente, y que ya no parecen buscar ninguna afirmación 
del sujeto, sino sólo algún ala bajo la que esconder la cabeza. En el mundo individualisıa de occidente, el individuo es precisamente lo que se encuculra más malirecho, para sorpresa de las ideas claras y distintas de Descarıs...29

Todas estas formulaciones irónicas tienen evidentemente sus peligros, pues de ninguna manera se puede tratar ahora de volver por detrás de la mo. dernidad, ni de regresar, si es que ello es posible, a antes de ella. No es asi. Pero en cambio si que debemos afirmar (aceprando incluso el riesgo de ese malentendido), que la consideración de los pobres como lugar teológico abre un camino de salida a esa lcología presa en la jaula dorada de la subjelividad. Dilícilmente esta tcologia, brotada de la modernidad, aceptará la acusación que le dirige el carácier (eologal de los pobres, y que puede formularse en continuidad con lodas las parodias que acabamos de hacer: "pienso... luego esioy en pecado:" Evidentemente, esta formulación es otra vez provocaliva; pero encierra un desenmascaramiento de la raiz. empecalada y empecaladora de la subjetividad. En delinitiva, ese cogito ergo pecco se aproxima bastante a la crítica al cogito de los Ires maestros de la sospecha Marx, Freud y Nietzsche, a los que cabria añadir a Sartre), que establecen la falsedad como categoría primaria de la conciencia: "pienso, luego miento." Y a través de ellos quizás nos acercamos bastante a esa vinculación entre pecado y mentira que encontrábamos en el cuarto evangelio.

Este detalle podria ayudarnos a entender porqué la espiritualidad cristiana, sensible ante esa raiz pecaminosa de la subjetividad, habia predicado siempre, como verdades teológicas, una serie de actitudes que hoy suenan igualmente intolerables para los teólogos de la subjetividad. Pensemos, por ejemplo, en la famosa indiferencia ignaciana: "pobreza que riqueza, salud que enfermedad, honor que deshonor, vida larga que corta"'... ¿quién puede escuchar eso serenamente? Pero ¿qué otra cosa nos dicen a nosotros, teólogos del primer mundo, los repetidos márlires de América Latina? Y sin embargo, hay que añadir para centrar el tema, que esa indiferencia ignaciana en modo alguno es una especie de resignación, de pasolismo o de nirvana, que confundirian la indi「erencia con la muerte o con un instinto desesperado de supervivencia "vegetal." La indiferencia ignaciana no es posible desde ahi, sino sólo desde la pasión por el Cristo "hecho pobre" y por el reino de Dios que llega para los pobres. En la indiferencia hay una experiencia de liberıad (y, por tanto, una redención de la subjetividad), como también la habia en el amor franciscano a la pobread pero de una libertad que no es mera expansion del sujeto, sino más bien su transformación en solidaridad y en compañia, en servicio y en comunión. Sólo ante la comunión se puede volver indiferenle la individualidad del individuo, como muestra a maravilla el ejemplo de la maternidad.

Y con esta calegoria de comunión frente a la pura subjetividad, podemos abordar teológicamente todo ese marco de la cultura moderna que suele calificarse como "Ilusiración," y cuya aceptación o rechazo de lugar (demasiado simplistamente porque la Ilustración es fenómeno muy complejo) a ser calificado como progresista y moderno, o como anticuado y reaccionario.

Como ya es sabido, la reacción de la lglesia ante la Ilustración no fue de- 
masiado gloriosa. El Syllabus de Pio IX pronunció una serie de condenas y estableció una imposibilidad de reconciliacion entre la Iglesia y el mundo moderno de la que, cuanto menos, hay que decir que era precipiada y también simplista, que se apartaba de la misión mesiánica de no apagar la mecha humeante y - sobre todo- que no había brotado de la solidaridad de la lglesia con los pobres, víctimas de ese mundo moderno, sino más bien del miedo de los poderes eclesiásticos a ser ellos las primeras victimas de ese otro "poder" de la razón moderna. El Vaticano II abrió muchas puertas que el Syllabus habia querido cerrar. Pero el contencioso sigue alí presente, reactivado hoy desde el seno mismo de la Ilustración, que también ella está comenzando a hacer su propia autocritica, porque tambièn a ella la Irabaja el Espirilu do Dios. Aunque esa autocrítica podria volverse estéril y ser abandonada, porque se hace con la sospecha de que ya no podrá detener las fuerzas que el aprendiz de brujo humano desató en la Ilustración.

La cara limpia y atractiva de la modernidad es de todos conocida y la vamos a dar por supuesta. Pero, a pesar de todo, la llustración como cualquier realidad humana es un fenómeno ambiguo, y sus relaciones con el cristianismo son más complejas de lo que parecen. Ilustración y fe cristiana afirman el carácter "divino" del hombre. Pero una lo afirma contra Dios, y la otra desde Dios. En sus comienzos la Iglesia se opuso a la Ilustración falsamente, es decir, porque se oponia a la "divinidad" del hombre, traicionando asi el evangelio que detenta. La ya lejana y conocida oposición de la lglesia a los "derechos humanos" fue la expresión de esa traición al evangelio, puesto que hoy es la misma Iglesia quien afirma que los derechos humanos brotan del evangelio. Al negar los derechos humanos en el siglo pasado, la Iglesia pretendia apelar a los "derechos de Dios," pero, en realidad, lo que estaba haciendo era buscarse otra divinidad más cómoda, o camuflar sus propios privilegios con el nombre de derechos de Dios. Pues el Dios que se reveló en Jesucristo es aquél cuyo derecho consiste en fundamentar y garantizar los derechos del ser humano. ${ }^{30}$

Pero, una vez corregida esa falsa dirección, quizás sea posible recuperar incluso lo que pudo haber de verdad parcial o mal formulada en el recelo de la Iglesia ante la Ilustracion: la crítica a la "divinidad del hombre" como propiedad privada del hombre frente a Dios. Ello nos serviría además para evitar el fenomeno de una aceptación precipilada y acritica (por lo que tiene de tardia) de la Ilustración, por muchos cristianos de la hora presente. Pues tampoco cabe negar, por lo que loca al mundo de habla hispana, que aquellos "afrancesados" de pasados siglos parecen haberse converlido en abuelos de muchos eclesiásticos "germanizados" de la hora actual, de los que uno ya no sabe si pretenden sólo ser "ilustrados," o si en el fondo no aspirarán a ser ilustres, o quizás "ilustrisimos" ...

Y bromas aparte, porque el tema es muy serio, queremos mostrar ahora que el punto de vista del pobre, la opción por la causa de los condenados de esta tierra, resulta ser el único punto de vista válido para llevar a cabo una confrontación entre Ilustración e Iglesia, hecha desde dentro de aquella misma, que es como debe dialogar siempre la Iglesia. En efecto, el pobre, por su misma realidad tan cruel y tan masiva, pone de relieve tres grandes agujeros de 
la Ilustración. Y además levanta la sospecha de que la causa de estos fallos pueda estar en que la llustración tomó la "divinidad" del hombre no como don de Dios (que por eso mismo es a la vez tarea libre y responsable), sino como "propiedad privada" tan absoluta que incluso autorizaba a excluir a Dios, y convertía al hombre en una verdadera mónada, incapaz de relacionarse con las otras mónadas si no era a través de alguna armonia preestablecida. Y coino esa armonia no se da, la relación habia de ser imposible.

Y esios tres grandes agujeros son, en primer lugar, el milo del progreso. Suena quizás duro hablar asi, y ahora mismo matizaremos. pero es necesario hablar asi para desenmascarar esa "mentira" del hombre que, a lo largo de este escrito ha aparecido muchas veces como su verdadero y último pecado. El progreso es ciertamente la voluntad de Dios sobre el hombre y, en este sentido, debe ser afirmado incondicionalmente, y un cristiano sólo puede ser "progresista." Pero esto no significa en modo alguno que sea progreso todo lo realizado por el hombre, y que sea fruto del progreso toda la realidad hisı́rica que tenemos hoy ante nosotros; ni que sea simple falta de progreso todo el dolor que agobia a nuestra hora histórica. No significa, por tanto, que el hombre no haya podido ser infiel a esa voluntad de Dios y no haya retrocedido muchas veces, aunque a lo mejor afirmase progresar. Pues sólo si el progreso fuese una ley infalible de la materia (materialismo dialéctico) o de la historia, podría excluirse esa posibilidad de la infidelidad humana.

$Y$ hay un detalle de nuestro mundo que obliga a pensar en este sentido. En el campo tecnológico - como han señalado también los críticos de la Ilustración $n^{31}$ basta que una cosa sea posible para que se haga. La razón técnica lleva implicito ese paso del poder al hacer, sin que resulten obstáculo ni los posibles riesgos, ni la utilidad cuestionable, ni la complejidad o las dificultades de realización de aquel proyecto posible. Factible ergo "faciendum, " es el primer mandamiento de la razón instrumental. En cambio, en el campo humano de la solidaridad y de la ética sucede al revés: aquello que es realmente posible es precisamente lo que deja no ya de realizarse, sino hasta de intentarse en serio, a pesar de la argumentación de Puebla que ya hemos evocado y que afirmaba que aqui es donde vale esa inferencia de la posibilidad a la obligación ${ }^{32}$ que el hombre realiza con su razón instrumental. Acabar con el hambre o con el armamentismo por ejemplo, son metas hoy ya técnicamente posibles; pero el hombre prefiere argüir que son infinitamente complicadas, y que podrian traer no sé qué riesgos temibles, a los que no se teme cuando se trata de producir hambre o armamentos. Esta doble medida (que no es sólo una medida "diferente," sino una medida invertida, puesto que debería funcionar exactamente al revés) es la que permite desenmascarar el mito del progreso, y la que da razón a estas palabras de la Congregación General 32 de la Compañía de Jesús:

A pesar de las posibilidades abiertas por la técnica, se hace más claro que el no está dispuesto a pagar el precio de una sociedad más justa y más humana... El hombre puede hoy hacer el mundo más justo, pero no lo quiere de verdad. Su nuevo seńorío sobre el mundo y sobre el mismo, sirve frecuentemente más, de hecho, para la explotación de los individuos y las colectividades y los pueblos, que para un reparto equitativo de los recursos 
del planeta; desencadena más rupturas y divisiones que comunión y comunicación; más opresión y dominación que respelo a los derechos individuales y colectivos en una real fraternidad. Las desigualdades y las injustjcias no pueden ya ser percibidas como el resultado de una cierta fatalidad natural; se las reconoce más bien como obra del hombre y de su egoismo. ${ }^{33}$

Estas palabras de oro se vuelven paradojicamente más Iransparentes a la luz de la resistencia y la conflictividad que han desatado. Y es que, afectivamente. sólo desde la comunidad con los pobres puede entenderse la crítica cien por ciento evangélica que ellos realizan. $Y$ a la vez, desde esa asunción de la causa de los pobres, es posible no la hostilidad contra la mistica moderna del progreso, pero sí la revelación de su pecado original: esa mistica ha concebido al progreso como puro enriquecimiento, sacrificando a este aspecto cualquier otra consideración. Con lo cual, ha embarcado a la historia en una marcha unidimensional y arritmica, donde todos los pasos adelante implican ahora alguna marcha atrás, es decir, se dan a cosıa de y cada vez. menos en beneficio de. $\mathrm{O}$, en todo caso, sólo en beneficio de esa misma idea de progreso convertida en un dios al que se sacrifica todo lo demás. Frente a esta situación histórica, hay que decir que sólo es progreso aquel avance que es verdaderamente humano y, por tanto, sirve a todos los hombres y a todo el hombre; no aquél que sirve a unos hombres a costa de otros, o a una dimensión del hombre a costa del todo. Desde esta perspectiva, la moderna noción de progreso queda desautorizada teológicamente. ${ }^{34}$ Por eso, Dios no responde a ese progreso con una epifania que corona el desarrollo humano, sino con su ocultamiento.

Y junto al mito del progreso, está el mito de la razón. Fue muy necesario erigir la razón y ponerla en pie contra las mil tiranias arbitrarias de la tradición o de la misma religión. Pero, a pesar de todo, la razón no es ninguna diosa como pensaban los ilusos fautores de la revolución francesa. Por inapelable que se presente infinidad de veces, son los pobres de la tierra, los infinitos sacrificios humanos que la razón moderna ha exigido, quienes la desenmascaran como idolo. Desde el hambre, y desde el dolor de los condenados de ta tierra, se percibe al menos la inhumanidad de una razón que exige gastar en armamentos - arrojar al mar lo que podria acabar con esta lacra del mundo moderno. La imposibilidad "práctica" de realizar esto, tantas veces invocada, sólo muestra la inhumanidad del sistema en que la "razón" nos ha introducido. Y con ello muestra que la razón, por muy necesaria que sea, y por mucho que haya que revindicar y defender su independencia critica, no es sin embargo, una apelación última, está sometida a algo que no siempre es "racional." Esta remitida a una ética que Kant ya percibió como situada en "otra razón," y está referida a una experiencia de "alteridad" y de misterio, que da lo mismo calificar como religiosa o no, pero que es innegablemente "suprarracional." Y la rebelión de la razón contra estas dos interpelaciones ha sido la causa de las tiranias establecidas en el mundo moderno, por encima ahora de la buena o mala voluntad de sus moradores ( $y$ casi siempre fuera de su alcance).

Pues con la razón ocurre algo parecido a lo que el joven Marx descubrió que ocurria con la religión. A pesar de su pretensión de universalidad, Marx 
constata, el comienzo de su camino, que la religión no es universal; al dios lc pasa lo mismo que a una moneda cuando cruza la frontera de olro pais; ha dejado de valer. ${ }^{35}$ Por eso Marx concluye con razón, que la religión no sirve de hecho para fundar una sociedad humana: es sólo una particularidad que se impone $y$, en cuanto lal, una fuente de opresión o de rebelión.

Pero Marx cree entonces que la verdadera universalidad reivindicada por la religión, se encuentra en la razón. A pesar de la innegable y casi tangible experiencia de universalidad que el hombre realiza en el ejercicio de su razón (fit quodammodo omnia decian los antiguos escolásticos), la realidad posterior demuestra, a veces con dureza, lo falso y lo tirano de aquella preconsión de universalidad: no exisle la razón, sino diversos lipos de clla; una razón instrumental, una razón politica... y hasta, por supuesto, una razón de estado. No existe la razón, sino una razón situada, como gustamos hoy de repetir. Es decir, existen lógicas que siempre son parciales y que el hombre no liene derecho a absolutizar procediendo como si fueran tolalmente universales, porque entonces transgrede sus límites y acıúa como Dios. $Y$ el resultado de cuando el hombre se pone a acluar como si él fuera Dios, son infaliblemente los condenados de la tierra.

Y creo que desde aqui si que es posible recuperar el " pienso luego estoy en pecado" con el que abriamos este apartado. Para empezar, los teólogos de la subjetividad deberian pensar alguna vez en algo que parecen haber olvidado y que está en la razón de nuestro drama actual; por qué será que la Biblia relaciona de algún modo el pecado de origen con el saber y el conocimiento (por ejemplo, Gen. 3: árbol de la ciencia; conocer el bien y el mal...). Buscar la universalidad en el conocimiento y, por tanto en el sujeto, puede ser para la teologia un "querer ser como dioses" comiendo del árbol de la ciencia. Pues acabamos de decir que al hombre no se le permite superar su particularidad más que en un quodamimodo, que el hombre convierte en absolute, pecando ahí. Al hombre no le es posible superar totalmente su particularidad, y menos cuando se trata de Dios que es la verdadera universalidad. Lo único que parece ofrecérsele al hombre es una particularidad privilegiada para su pensar; y ésta son los no-hombres, los pobres.

Concluimos, por consiguiente que la nueva categoría a introducir es la de razón dialogal, frente a la razón individual de la modernidad. Y señalamos cómo casi todas las grandes inmoralidades de nuestro mundo no son más que la lógica (cuanto más férrea más inmoral) de una razón individual: empezando por el capitalismo, la mayor de todas ellas. ${ }^{36}$

Y en tercer lugar, como consecuencia de las dos anteriores, la revelación más dura, pero la más necesaria, la verdad del mal. Da lo mismo que le cambiemos el nombre y que le llamemos "mal" en vez de pecado. La terca realidad de los pobres nos lo sigue gritando al rostro: el hombre es un ser culpable. Da lo mismo que nos tapemos los ojos y los oídos, incluso que pretendamos acabar con los que nos gritan eso: el pecado está ahi, y es el hombre quien lo comete, aunque se engañe al cometerlo o para cometerlo. La cultura moderna asiste también a afanes desesperados por inocentar la riqueza, o por inocentar el poder o por inocentar la sexualidad. Afanes tan desesperados que es muy cu- 
rooso observar la indignación de los defensores de todas esas inocencias, cuando alguien trata de enfrentarles con la realidad de todas aquellas dimensiones de la vida, no para decir que son malas, pero si para recordar que son ambiguas que no es posible jugar con ellas con la inocencia de un juego de niños porque llevan dentro una carga muy explosiva y que, por consiguiente, el hombre debe afrontar esas dimensiones con responsabilidad y atención a los demás... L.a ira que todas estas observaciones engendran en los defensores de la inocencia de la riqueza, del scxo o del poder, resulta ser la sospecha más crasa para una cultura que busca "maestros de la sospecha." El capilalisia pretende que su injusticia es el "Iruto legílimo de su trabajo" y inonta en cólera cuando se le sugiere que quizas ha desconocido a su compañero de Irabajo. El autor de fisiologías utópicas que afirma "liberar a la mujer," monta en cólera cuando se le dice que quizás no ha hecho más que desconocer a la mujer. Y el tirano monta en cólera cuando se le dice que ha negado al hombre, porque èl pretende que lo ha servido. La referencia a las victimas es algo que esios hombres no pueden tolerar. Eso es lo que los vuelve lan sospechosos. ${ }^{37}$

En resumen, las calegorias del progreso solidario, de la razon dialogal, y la de las víctimas, son las tres nociones que los pobres aportan a la teologia para su diálogo con el mundo de la llustración. Esas Ires categorias lodavia deberán formalizarse mucho más, pero eso ya no puede ser larea de este largo escrito. Lo importante para nosotros es la consecuencia que todo ello tiene para la Iglesia, y que, para concluir, Iormularíamos así: dificilmente podrá haber una confrontación válida entre cristianismo y modernidad, o entre leologia y cultura actual, si para hacerla no se sitúa el cristianismo en la cultura que brola de la asunción de la causa de los pobres, de todos los pobres y de todas las clases de pobres de esta tierra.

\section{CONCLUSION}

Ante la realidad de los condenados de la tierra - y por eso nos son tan molestos- es casi imposible hoy el abstencionismo. El no tomar postura ya es, en la mayoria de los casos, una toma de postura. Y cuando el hombre está ante ellos en una postura negativa, es decir, insolidaria, está negando con esa postura práctica la realidad y el valor de la solidaridad. ${ }^{38}$

Y quien, con su postura práctica está negando la realidad y el valor de la solidaridad, será muy dificil que luego pueda aceptar la revelación de un Dios que es Solidaridad, y que no se revela como poder sino como amor débil y fiel hasta el extremo. Tal revelación parecerá necesariamente locura, o escándalo, parecerá utopia ingenua o subversión delictiva. O parecerá insuficientemente fundada para lo mucho que exige. Y lodo esto lo parecerá en un rejido argumental de suficiente coherencia: "¿acaso no sabemos que éste es de Galilea y que el meslas ha de venir de Belén?"' (Jn. 7,41.42), era, por ejemplo, un argumento irrefutable en apariencia. Pero el mismo evangelista nos dirá después que la clave de la fuerza del argumento es otra; ese era el argumento de los jefes $(J n, 7,52)$ y ninguno de los jefes había creido $(7,48)$.

O con otras palabras; lo que, ante Dios, decide sobre fe o no-fe, no son 
nuestras informaciones acerca de Bclén o Galilea, sino este orro hecho que Rahner ha puesto tantas veces de relieve: que a Dios sólo se lo alcanza atemáticamente ( J Jn. 4,20, no se le ve). Sólo sc lo alcanza como horizonte trascendental. Incluso cuando se categorializa o se tematiza a Dios, en ese acto se lo alcanza también alemáticamente; la sola calegorización de Dios seria un idolo. Y el mayor lugar atemático de ese alcance a Dios es "la apertura amorosa y confiada hacia la totalidad de la realidad que sucede en el amor" al pobre.

Y nada de lo dicho implica una absolutización de los elementos "culturales" (es decir, históricamente condicionados) que liene la mediación del pobre. Como ya reconoci en otra ocasión parecida, esa mediación podrá lomar otros nombres en otras situaciones culturales e históricas, el pobre es paradigma del oprimido. Y, al comienzo de este escrito, aludiamos a otras situaciones de opresión, como la racista, que tambièn están dando lugar a otras teologias de la liberación, tanto en Estados Unidos como en Sudáfrica. Si, puestos a soñar, alguien imagina un mundo en el que la justicia haya sido satisfactoriamente realizada y la pobreza satisfactoriamente vencida, y le surge la pregunta de dónde quedará alli el "lugar teológico" que hemos descrito aqui, la única respuesta es esta: eso ya se verá entonces. Nosolros sólo afirmamos que hoy y aqui, en el planeta tierra y en 1985, los pobres constituyen un lugar teológico en el sentido descrito.

Y si todo esto es asi, entonces podemos concluir reformulando, para nuestra hora histórica, la clásica tesis agustiniana de las dos ciudades. Podemos decir simplemente que estas dos ciudades consisten en "amarse a si mismo hasta el desprecio del pobre, y amar al pobre hasta el desprecio de si mismo." Pero bien entendido que esa formulación, sólo aparentemente provocativa, no pretende sustituir en modo alguno a la formulación de Agustín; sólo pretende hacerla posible al marcar el camino que hoy lleva a ella.

\section{NOTAS}

1. Aún hoy, ell el seno de la Iglesia calölica, se pretende hacer lo mismo con el magisterio eclesiástico, al que algunos de sus guardianes milifican negándose a someterlo a toda una hermenéutica humana, a la cual la misma palabra de Dios de la Escritura se ha sometido. ¡Como si el magisırio eclesiástico fuese "más" Iugar ıenlógico que la Escritura! Con ello, por supuesto, no se defiende al Espiritu Santo, sino la tranquilidad de quienes deberian ser sus instrumenıos más dóciles.

2. cf. James Cone. Teología negra de la liberacion. Buenos Aires: Lohlć, 1973. O ni presentación de ella en Actualidad Bibliografica de F. y T., XII (1975) 355-36I.

3. Ver Principalmente la Contribucion a la crítica de la filosofía del derecho de Hegel. en $\mathrm{K}$. Marx - F. Engels, Sobre Ja religion, Salamanca, 1974, 105-106.

4. Otra cuestion muy distinta es si efeclivamente las diversas teologias han cumplido con esta obligación.

5. O. Tuñi, El tessimonio del evangelio de Juan, p. 132. Los subrayados son mios. Y aunque no sean estrictamente lo mismo el ser "mas resiringido" y ser un "momento" que el ser posterior, me parece que ell el caso de Juan, si que lo son.

6. "“Ni siquiera son dioses!" exclama Jeremias $(2,11)$ y cs quizás el primero que lo dice asi de claro.

7. Pues este malentendido es inherente a la razón loumana, y pucdo poner de él dos ejemplos ajenos al contexto que ahora ıraımos. Una vez que la lglesia dejo de isıar crucificada, ha 
hablado muchas veces de la misma cruz desde una theologia gloriae, aunque para ello haya tenido antes que bajar de la cruz al crucificado: la Iglesia ha convertido la cruz en alhaja, en emblema de poder para sacralizar a sus autoridades, en razon politica que llevaba incluso a hablar de "cruzadas" (jjamás se insistirá bastante en la contradicción leologica que esta palabra encierra!). Y codavia olro ejemplo, es muy distinıa la manera como, en la ICor, habla Pablo de la cruz como lugar teológico, de la manera como podria hablar desde un gabinete cualquier pensador brillanic e ingenioso, que nos dijese por ejemplo que la cruz es revelación de Dios porque su figura universaliza, uniendo cielo y tierra, izquierda y derecha, etc. Esie segundo modo de hablar podrá ser aceptado, o podrá ser atacado como mitificación de la cruz. Pero lo único que ahora nos interesa constalar es que no es ese el modo primario como habla Pablo.

8. Curiosamente, la iglesia "oficial" que se ve en este punto acosada y acorralada por el evangelio, se muestra más dispuesta a aceptar la desinstalación que produce el pobre como individuo aislado que como grupo, clase, pueblo o conjunto de pueblos. Y es que lo primero aún puede ser vivido como mérito, puede ser resuelto de una manera sólo asistencial (sin cambiar de posicion) y proclamado como obra buena propia. Mientras que lo segundo nos exige una conversión mucho más profunda, y nos deja como sin salida entre la espada del evangelio y la pared de los poderes de este mundo.

9. Por otro lado, la alusión al donatismo como punto de comparación quizás no sea muy afortunada si recordamos lo poco que tuvo el donatismo de problema doctrinal y propiamente teológico: Donato no hizo más que buscar argumentos para un conflicto previo de pasiones, en el que anduvo en juego la sucesión al obispado de Carlago, y en el que se hermanaron la debilidad de Mayorino con las presiones de Lucila, rica dama espałola que vivia en Africa y cuya histeria era de esas que, por si solas, hacen a veces excusable el antifeminismo... VEase por ejemplo D. Rops, La Iglesia de los apósioles y de los máritires, Barcelona, 1955, 458-464.

10. "Técnicamente es posible la producción de los bienes que necesita la humanidad, incluido, por supuesto, el tercer mundo. Se ha llegado a pronosticar que si hoy se utilizasen e introdujesen racionalmente todos los conocimientos tecnológicos (la mayor parte todavia mantenjdos como secreto militar y empleados en la carrera armamentista y del espacio), se podria producir lo necesario para la humanidad "trabajando la población en edad laboral sólo dos horas al dia" o, lo que es lo mismo, tres dias a la semana, o cineo meses al año durante quince años, a tiempo completo, de la vida activa de una persona." Conclusiones del Seminario del Centro Cristianisme i Justicia, sobre Trabajo, paro y planificación del futuro. Barcelona, sepliembre de 1984, (ejemplar mimeografiado). Doc. 2, p. 4.

11. Y nótese como estas observaciones nos llevan a la misma conclusión que el apartado I. Si después de lo dicho ocurre en esios tiempos que "Dios calla en el primer mundo" o que el primer mundo se va descristianizando sistemáticamente, es preciso que la Iglesia se pregunte si eso es simple f́rulo de algún proyecto cultural anticristiano contra el que hay que cerrar filas y hacer eruzadas, o si es simplemente la respuesta de Dios al pecado del primer mundo para con los pobres: a su negativa a decir "Padre he pecado" cuando se tropieza con los pobres de la tierra. Y esta respuesta consiste como ya sabemos en que Dios "los entregó a los deseos de su corazbn" porque cambiaron la gloria de Dios (que es la vida del pobre) por sus propios idolos de progreso: "de suerte que su insensato corazón quedó en tinieblas y alardeando de ser sabios cayeron en la necedad" (ver Rom. 1,21-28).

12. Véase como aplica esto mismo Jon Sobrino a la teologia de la liberación como distintivo frente a la teologia del primer mundo en "Teologia de la liberacion y teologia progresista europea," Misión Abierta 77 (sept. 1984).

13. Ese mecanismo de autodefensa actúa muchas veces en el seno de la misma Iglesia, dado que esta no puede negar lo evangélico del tema y de la interpelación de los pobres. Y una de las formas de esa actuacion es, entre nosotros, el llamado "anticomunismo" entendiendo por tal esa actilud que teme al comunismo más de lo que cree en Dios y que es hoy frecuentisima. Entonces se dan más o menos los siguientes pasos: toda acción favorable a los pobres es tachada de comunismo o de algo que lleva fatalmente a él; bien sea porque la hacen los comunistas, bien sea porque se infiltran entre quienes la hacen. Este es el mensaje subliminar que transmite siempre la derecha y que, por supuesto, tiene su dosis de verdad, dado que los ricos no hacen absolutamente nada por los pobres... De este modo, lo único que le queda al cristiano es reivindicar un amor leórico y abstracto a los pobres, pero que no puede ser pues- 
to en obras porque implicaría un peligro mayor. De esle modo. episcopados casi integros como el argentino, ha cohonestado siluaciones de las más criminales que ha vivido la humanidad, como ocurrió en liempos de la dictadura militar. Sin haber aprendido ulla leccion pare. cida de los obispos alemanes cuando Hiller, ni de los espafioles cuando Franco. El anicomunismo se convierte así en un fin absoluto que justifica toda clase de medios. hasta el enterrat el ialento evangélico y el pasar de largo como el sacerdole y el leviı de la parábola anıe el hermano caido en la cuneta. Esta deserción en bloque, deja muchas veces solos a quienes quieren oplar por los pobres, convirıiéndolos unas veces en carne de nıártir, o radicalizándolos desesperadamente otras. Con esto último, st confirma el pumo de parlida de que toda acción por los pobres llera fatalmente al comunismo. Y el mecanisno de autodefensa sale triunfance.

14. Esıc juicio vale al menus para hoj co dia, cuando como afirnía Pucbla, climinar la pobrea es posible, y si es posible es obligatorio (No. 21). No querenos entrar ahorat en juicios hisıoricos más absolutos.

15. Iglesia que nace del pueblo: una buema noficia. Mévico, 1978, pp. 26-27. Respecus a sul libulo que, como se sabe. contiene una expresion clesillorizada. me permilo llamar la alencion sobre la fecha de publicación.

16. Esta es, en definitiva, el drama de los socialismos reales: en sus valores y en sus dioses resullan lan burguesen como el capialismo, y solo difieren de el en los gestores de esos salores y los sacerdotes de esos dioses.

17. Obras, BAC, p. 541 .

IR. Jon Sobrino, "Hacia una deferminacion de la realidad sncerdotal, " en Revisia Latinoamericana de Teologia, I (1984) 47-61.

19. La lectura que hacian de este texto los lariseos en ticmpo de Jesis era: sean separados como yo soy separado (foriseo en hebreo equivale a separado). Aqui se ve más claramente lo pole. mico de la formulación lucana.

20. Sobre la Iraduccion de "el Hijo del Hombre", por El Hombre, ver, La Hamanidad Nueva (6a. ed.), $231-250$.

21. Ver G. Guliérrez, "Teologia desde el reverso de la hisıoria," en La fuerza hisıórica de los pobres, Lima, 1980, p. 303ss.

22. "Comprender por que la humanidad (tras la llustración) en lugar de entrar en un esıado verdaderamente humano, desemboco en un nuevo género de barbarie." M. Horklıeimer y $T$. Adorn, Dialectica del iluminismo, Buenos Aires, 1971. p. 7.

23. Recuèrdese lo dicho subre la gloria de Dios en el aparado anlerior. De acuerdo con ello cabria traducir: lodos esıán necesilados de la vida que da Dios. Lo que empalnia a maravilla con la vinculación pecado muerte tipica de la Biblia, y que permitiria iraducir así la primera parte de este versiculo: "lodos estin muerlos" como hombres.

24. Vale en este sentido los que a veces se dice, que el pecado es la pobreza radical de lodos los hombres. Pero no en el senıido de que eso haga una nivelación o indisınción enıre pobres y ricos; cso seria sólo un uso ideologico de esta verdad, que lejos de hacer superflua la opcion por los pobres, mostraria el pecado de quien asi habla. Pues el pecado de rico (que lo hace "pobre" anle Dios) es precisamente su insolidaridad y su causalidad respecto de los pobres de la tierra.

25. He tratado este mismo punio en "Crisıo juslicia de Diox. Dios justicia nuestra", en AA.VV. La justicia que hrola de la fe, Santander. 19A3, nrincipalmente pP. 145.146 al hablar de la fe que justifica como un creer a Dios, más quc un mero creer en Dios. Tambièn en el comentario al Magnificat en "Maria: inemoria de Jesis: memoria del pucblo" en Memoria de Jesis. Memoria del pueblo. "Santander, 1984, pp. 22-29.

26. No hay en esta frase una milificación del pobre, como tampoco la habia enl los lextos citados en las notas is y 17 . Súlo se irala de mosirar la impoicencia creyente del canino del rico, la cual se hace perceptible tambic̀n en las excelentes reflexiones de E. Jüngel sobre la fe (er. Dios como misterio del mundo. Salamanca, 1984, p. 496): creer es no poscerse a si mismo, de modo que "quien se posee a si mismo, no cree." Por el contrario, "la fe en su esiruciura formal (determinada ciertamente por el llamado contenido de la fe), es expresión existencial de que el hombre no se posee a si mismo," y de que este no-poseerse-a-si-mismo "no es una carencia" sino "un beneficio antropológico." De este modo, la fe expresa que la actilud primaria del rico, que es "la autorreferencia del ıener, broıa de una aciliud allıropológica equivocada, 
que está orienıada al irato o comercio con las cosas que se pueden poscer." Esıa actitud pri. maria es la que impide la fe como desposesion; y por eso es tan dificil que el rico se salse (M: 10,23).

27. En oposición a la edad media caracterizada por la objetividad y tl tradicionalismo. Y. Congar caracteriza al mundo moderno por la subjetividad y la invesigacion. Y define la subjelivided asi: "el descubrimiento del sujeto y del papel del sujelo. Descubrimientu del honbrt. de sus posibilidades, del papel que desempentan sus disposiciones en la pitcepción y aun en lá cosntrucción de la verdad." Falsas y verdaderas reformas en la /glesio, Madrid, 1953, p. 454.

28. Con ello no me estoy refiriendo a conductas sino a justificaciones. Las conductas humanas aproximadamente, son siempre las mismas. Y la hisioria es una macsira compciente para curar de espantos y garantizar que no hay demasiadas cosas nuevas bajo el sol cle lex hoinhres. Los creyentes no deben cocaramarse a ninguna Iribuna de moralista apocalipuicu, sino dejar a Dios su papel de jue, misericordioso, con la seguridad de que lo hará muclu mejor que ellos.

Pero, además de las conducıas, esıán, como digo, Jas justificaciones o la manera de viv ir csas conducias. Y si los comporiamienıos en el fondo varian poco, las justificaciones en eamibiu son mucho más diversas, y son las que perıniten apunıar esa Irayecioria insinuada en el Iexıo. Y esıa observaciòn debe generalizarsc, de modo semejante cabe decir qui la subjelividad ha existido y ha sido pecadora ya antes de Descartes. L o nuevo de la moderniclacl seria el erigir esa experiencia ambigua del sujeto en punto de pariida de Ioda seguridad posible:

29. En el campo filosolico, el estructuralismo se presenta como una nueva "objetividad" aún más realisı que la de los sistemas medievales, y hace aǹicos la preiensión del ergo... corlesiano. Y a un nivel más divulgador, pero, para mi gusto, extraordinariamente bien realizado. permitase aludir a algo de esıe mismo proceso. citando una de las úlıimas novelas menores de M. Delibes, las Corias de amor de un sexagenario volummoso. donde ya el litulo resulta ser de una forma tan imperceptible como despiadada, y que inaugura esta misma ceremoniosa crilica: la subjetividad no aparece alli condenada, sino algo peor, ironizada con maestria. $Y$ el lector, al acabar el libro, no puede menos de parodiar exclamando: "pienso, luego soy ridiculo."

30. Ver el volumen de AA. VV. La Justicia que brota de la fe, Santander, 1983.

31. Por ejemplo, M. Horkeimer, Crítica de la razon instrumenial, Buenos Aires, 1973. H. Marcuse, El hombre unidimensional, Barcelona, 1966.

32. Ver supra nola 14.

33. Nos. 20 y 27. Los subrayados son mios.

34. Y no soblo teológicamente. Es importante notar cómo la teologia confluye aqui con lo mejor de la culiura moderna, como estos dos textos muestran, uno del primer mundo y orro del rer. cero:

a) Si la aventura del progreso, tal como hasia el dia la hemos entendido, ha de traducirse inexorablemente en un aumento de la violencia y la incomunicación. de la aulucracia y la desconfianza, de la injusticia y la prosıitucion de la naluraleza, del sentimienın competitivo y del refinamienio de la tortura, de la explotación del hombre por el hombre y la exalración del dinero, en ese caso yo gritaria ahora mismo con el prolagonisıa de una conocida canción americana: que pares la tierra, quiero apearme (M. Deliber, Un mumdo que agoniza, Plaza Janés. 1970, p. 166).

b) "La fraternidad es el camino de retroceso a la barbarie. Dios creo al hombre desigual tu facultades. Eso no tiene remedio. Hay que respetar y perfeccionar la obra de Dios. La desigualdad como motor de lucha y de ascenso." Asi habla don Fermin Aragón de Peralia, un gran defensor del "progreso" en la novela de J . M. Arguedas, Todas las sangres, Madrid, 1932, p. 242.

Ambos textos parecen mostrar que se ha cumplido el proverbio atribuido nada menos que a Rabelais: ciencia sin conciencia no es más que la ruina del alma.

35. Ver Sobre la religion; Op. cii. 60-61 y 71-83.

36. Esa lógica a la que un buen comentarista de Adorno ha calificado como "lógica de la ruina." Ver. J. E. Schmocker, Adorno. Logik des Zerfolls. Siultgart, 1977.

37. 'La vida amenazada de los pobres muestra la verdad de toda la humanidad; verdad que, por ser pecado, busca ocultarse activamente." J. Sobrino, "Lo divino de luchar por los derechos humanos," en Sal Torrae, oclubre de 1984, p. 690. 
38. Aclaremos que insolidaridad no es lo mismo que impolencia, aunque la menira humana podrá en muchos casos servirse de la impotencia como excusa para la insolidaridad y es evi. dente que de la existencia concreta de estas conduclas no jugamos los hombres, sino soblo Dios.

39. Escriros de reologia VI, 289. Rahner dice amor "al projimo." Pero vale aqui lo que deciamos al comienzo de esıe articulo, a propósito del buen samarilano: el projinıo no es el que csıá cerca de mi, sino el que tiene necesidad de que yo me aproxime. 